\title{
A Supply Chain as a Network of Auctions
}

\author{
Thierry Moyaux, Peter McBurney and Michael Wooldridge \\ Department of Computer Science \\ University of Liverpool \\ Liverpool L69 7ZF, UK \\ \{moyaux, p.j.mcburney, mjw\}@csc.liv.ac.uk
}

July 17,2007

\begin{abstract}
This paper proposes and evaluates a model of supply chains as networks of auctions. In this model, companies are represented according to the first level of the Supply Chain Council's SCOR model and the trading strategy of the agents is adapted from a model proposed by Steiglitz and colleagues. Specifically, the highest level of SCOR treats a company as comprising three functions, namely Source, Make, and Deliver. Our companies may also have these three functions, where Source and Deliver are modelled in a way similar to the agents proposed by Steiglitz and his colleagues, that is, they hold products in their inventory and place shouts to buy or sell products so that their inventory remains at its target level. After presenting our model, we study its behaviour with a simulation based on the JASA auction simulator. This study provides insights into supply chain dynamics and associated trading behaviours. In particular, the simulation results show that price dynamics are more complicated than simply balancing consumption, transformation capacities, and the supply of raw materials. In addition, we identify three patterns of price dynamics in our auctions, explain their cause, and propose rules linking initial conditions and the occurrence of such price patterns.
\end{abstract}

Keywords: Supply chain modeling, SCOR Model, Auctions, System dynamics, Agent-based Simulation.

\section{Introduction}

Supply chain management is one of the most widely studied problems in contemporary manufacturing and industrial management (Simchi-Levi et al., 2000). Supply chain management involves the design, modeling, implementation, and coordinated control of networks of resources in order to supply goods and services to consumers. Typical goals are to build supply chains that are, for example, agile (able to respond rapidly to changing market circumstances), lean (with the smallest possible commitment to items in stock), and robust (resilient against unforeseen logistical problems). Improvements in supply chain management can yield significant competitive advantage for producers, hence the considerable interest this subject has aroused.

One increasingly popular approach to the design and management of complex systems is the use of market mechanisms - see e.g., Clearwater (1996). Markets are widely recognised as providing efficient mechanisms for resource management and allocation. Historically, the inevitable coordination and management overheads associated with implementing market-based systems have meant that their use has been reserved for large applications. However, the widespread availability of cheap networked computer systems has meant that the overheads associated with operating market systems are now sufficiently low that they can be much more widely used (witness, for example, the growth of online auction-houses such as eBay). 
It is not surprising, therefore, that researchers would investigate the use of market mechanisms for supply chain management. An interesting market-based system in which traders produce and consume goods was Steiglitz et al. (1996). In this paper, we build on their work. As part of a larger project to apply concepts from economics to the design and management of distributed computational systems, ${ }^{1}$ we have studied supply chains as sequences of linked marketplaces. In this model, entities in the chain exhibit buyer/seller behaviours, rather than, for example, order/deliver behaviours (as in the Beer Game (Sterman, 1989)). In this model, a supply chain then consists of sets of market interactions involving three connected flows up and down the chain: needs, goods, and money.

Our work builds on the prior work of Steiglitz et al., as follows. Essentially, we have adapted their model to networks of auctions in order to utilize their tools (speculation, and the three price signals) in the management of supply chains. For that purpose, we have replicated the experiments in these three papers $^{2}$ using the JAVA Auction Simulator API (JASA) ${ }^{3}$, and study how these results scale to networks of auctions. Our aim, therefore, is to understand if tools effective for management of the dynamics of a single auction remain effective in the presence of supply chain dynamics; that is, to understand if these tools can also handle the different streams (needs, products, and money) in supply chains, as well as the interactions among these streams. With regard to such adaptation of tools, we have already stabilised the prices in a supply chain modeled as in this paper by means of speculation (Moyaux and McBurney, 2006b). We also plan in (Moyaux and McBurney, 2006a) to adapt the methodology proposed by Mizuta et al. (2003) to broadcast different price signals in order to stabilise supply chains. However, adapting such tools to supply chains is not the topic of this paper, which focuses on the model and its dynamics.

The remainder of this paper is structured as follows. Following a survey of related work, Section 3 introduces our model. Section 4 presents the dynamics of the price when a single market is considered. In particular, we identify three patterns of price dynamics, explain their cause, and propose two rules linking such patterns with some initial conditions of the simulation. Section 5 extends these observations and explanations, and adds a rule in a scenario with two sequential markets. Finally, Section 6 concludes the paper.

\section{Background and Related Work}

According to Dodd and Kumara (2001), Mark S. Fox was probably the first to model a supply chain as a multiagent system (Fox et al., 1993). Besides the construction of an agent-oriented software architecture (Fox et al., 2000), Fox and a colleague of his have proposed COOL (COOrdination Language), a language based on KQML for coordinating industrial distributed applications (Barbuceanu and Fox, 1996). Many other applications of multiagent systems to supply chain management have followed. For instance, Cloutier et al. (2001) also worked on coordination by proposing CAT (Convention, Agreement and Transaction) to the bus manufacturer Prévost Car. ${ }^{4}$ CAT allows business partners to share high level information, next interact (e.g. negotiate) with each other, in order to commit on punctual manufacturing or informational actions to perform in the future. Another example is provided by Anthes (2003) who reports that Procter \& Gamble "saves USD300 million annually on an investment of less than $1 \%$ of that amount" thank to agent-based simulations. In fact, Nutech Solutions (former Biosgroup $^{6}$ ) provided Procter \& Gamble with an agent-based simulation of a portion of its retail supply network in order to study the impact of certain policies applied by the companies in this network. Next,

\footnotetext{
${ }^{1}$ See http: //www.marketbasedcontrol.com/

${ }^{2}$ We not present our replication here of the results of the three papers by Steiglitz. Note that when we refer to these papers, we refer in fact to our replication of their models.

${ }^{3}$ See http://www.csc.liv.ac.uk/ sphelps/jasa/ and http://jasa.sourceforge.net/.

${ }^{4}$ See http://www.prevostcar.com/.

${ }^{5}$ See http://www.pg.com/.

${ }^{6}$ See http://www.biosgroup.com/lit_featured.asp and http://www.nutechsolutions.com/ lit_featured.asp.
} 
additional studies are more focussed on the use of markets in supply chains. The Trading Agent Competition - Supply Chain Management (TAC-SCM) ${ }^{7}$ may be the most famous model in this category. As indicated by its name, this is a competition in which entrants propose software trading agents in order to buy components from several suppliers, assemble these components, and sell the finished products to end customers, all automatically.

Such a model of a market-mediated supply chain allows studying questions as the long-term costs and benefits in a business-to-business (B2B) context of online auctions in comparison with a longterm relationship. In other words, is it better to have a market-mediated supply chain in which the competition among traders leads to the short-term optimal, or a traditional RFQ/RFP (Request for Quote/Proposal) process in which learning may end with a better long-term result? (Geoffrion and Krishnan, 2003, p. 1147) In addition, markets are often thought to be efficient when they are perfect, but are they able to handle the complexity of supply chain dynamics due to their interconnected flows? Markets may therefore be an efficient way to manage supply chains.

In the model of Steiglitz et al. (1996), a single type of agent produces food and gold, then trades food for gold via a market modelled as an auctioneer. Two kinds of speculators are also introduced, which both stabilise the clearing price when no price bubbles are created. Subsequently, Steiglitz and Shapiro (1998) extended this initial study of the model by analysing the occurence of these price bubbles and interrupting them during their formation. In both papers, trading agents bid a price calculated as $P(t-1) * B(\bar{f}, \bar{g})$, where $P(t-1)$ is the previous price in the auction, and where $B(\bar{f}, \bar{g})$ is a function of the internal state of the agent (this strategy will be detailed in this paper). Later, this model was extended to understand how an auctioneer can stabilise the price in a single auction by broadcasting more information about the state of the auction than simply the actual clearing price (Mizuta et al., 2003). Specifically, the auctioneer broadcasts one of the following price signals: (i) $P 0$ is the non-weighted average of the prices in all (bid and ask) shouts, (ii) $P 1$ is the average of the prices in all shouts weighted with the quantity of these shouts, and (iii) $P 2$ is another weighted average of the prices proposed by the traders. Next, the traders then bid the price $P 0(t-1) * B(\bar{f}, \bar{g}), P 1(t-1) * B(\bar{f}, \bar{g})$ or $P 2(t-1) * B(\bar{f}, \bar{g})$. When the auctioneer broadcasts $P 0$, then $P$ slowly reaches its equilibrium; when $P 1$ is broadcast, then $P$ fluctuates forever; finally, using $P 2$ causes rapid convergence to the equilibrium.

The problem with Steiglitz et al.'s model is the assumption that, in every round, traders decide to produce either food or gold. Such an assumption replicates an economy of ancient time in which the agents are not specialised on a specific production activity. In stark contrast, the agents in modern economies are very specialised: either they are farmers who grow food, or they are miners who dig for gold. Such a specialisation generates an interdepency among the two types of agents: farmers rely on miners to fulfil their needs in gold, while miners have to trade with farmers in order to obtain the food they consume. Since miners always sell gold and buy food, two streams flowing in opposite directions appear, namely a stream of food linked to a stream of gold. This way, miners and farmers form the most simple supply chain.

In this paper, we first study such a simple supply chain with only two types of agents, in which the miners are called end customers because they are the source of money, and the farmers are seen as raw material producers because they provide end customers with products. Then, we extend this model with a third kind of agents, called manufacturers, that transform the products bought from the raw material producers in order to sell the transformed items to the end customers. This model is thus quite similar to the TAC-SCM. Since two kinds of products are exchanged among these three types of agents, two markets are required, i.e. one market per product type. We think that such an improvement over Steiglitz et al.'s model does not only make it more realistic with regard to modern economies, but also sheds light on the different interdependencies in supply chains. In fact, the different streams traveling accross supply chains cause both the markets and the different types of traders to be interdependent. For instance, the fluctuations of the price in the first market may impact on the fluctuations of the price

${ }^{7}$ See http://www.sics.se/tac/. 


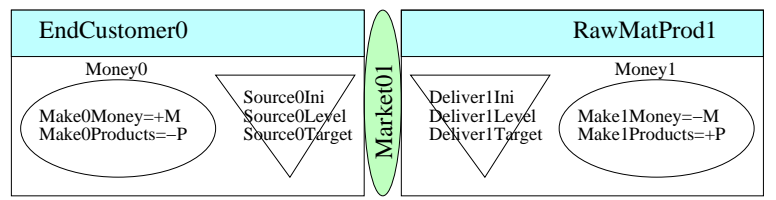

(a) The two types of agents trading in one Market 01 .

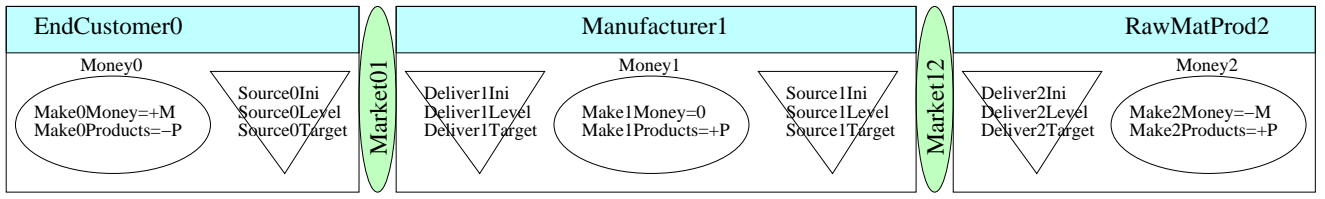

(b) The three types of agents trading in Market 01 and Market 12.

Figure 1: The two structures of supply chain considered in this paper.

in the second market.

The model with two and three types of company-agents is now introduced.

\section{The Supply Chain Model}

Our aim in this section is to give a detailed description of the supply chain model whose properties we subsequently investigate. The basic idea of the model is simply that the supply chain itself is modelled as a chain of interconnected markets. Thus, for example, a market connects raw material producers to manufacturers, and another connects end customers to manufacturers. Our belief is that by building supply chains in this way, we can in particular make them more efficient and more responsive to prevailing market circumstances.

Our model makes use of the first level of the Supply-Chain Operations Reference-model (SCOR), and we describe how SCOR is used in our model in Subsection 3.1. The ordering strategy used by companies in our model is described in Subsection 3.2. The use of the JASA auctioneer in the model is described in Subsection 3.3. Finally, some definitions and the settings of parameters conclude this section.

\subsection{The Companies Modelled with Supply-Chain Operations Reference-model (SCOR)}

There are three types of entity in our model of a supply chain:

- End-users (denoted EndCustomer0),

- Manufacturers (Manufacturer1), and

- Producers of Raw Materials (RawMatProd1).

These different entities are illustrated in Figure 1(b). Manufacturer 1 in Figure 1(b) is modelled directly according to the first level of SCOR, while the other four companies in Figures 1(a) and 1(b) are simplifications of this model. The three functions Deliver, Make and Source directly correspond to $\mathrm{SCOR}^{8}$. We will use "inventory" to refer to a Deliver or a Source as an agent holding products in inventory and bidding in an auction. Companies, such as EndCustomer0, are also agents (their activity is called Make) which encapsulate inventory-agents. We use "she" for Sources, "he" for Delivers and "it" for their company. In more detail, the companies in Figure 1 have the following functions.

EndCustomer0 in Figures 1(a) and 1(b) has two functions:

\footnotetext{
${ }^{8}$ SCOR also considers two Return functions in parallel with Deliver and Source, and a Plan function controlling the five other functions.
} 
- Make0 produces Make0Money $=+M>0$ units of money by adding this quantity to Money0, and consumes Make0Products $=-P<0$ units of food in every round. The consumption of products is achieved by removing them from the inventory Source0. If EndCustomer 0 cannot consume the quantity Make0Products, then it forgets this fact in the future (i.e., it neither dies nor tries later on to consume more to compensate for a past lack of food).

- Source 0 is an inventory-agent who bids in Market01 in order to buy products so that her inventory level Source0Level is kept at Source0Target. She starts the simulation at level Source0Ini. The products are paid with Money0. The bidding strategy is the one introduced by Steiglitz et al. (1996), and presented in Subsection 3.2.

Manufacturer1 in Figure 1(b) has three functions:

- Deliver 1 is an inventory which uses Steiglitz et al. (1996)'s bidding strategy to place ask shouts in Market01. The goal of Deliver 1 is to sell products so that the level of Deliver 1 stays at Deliver1Target. Money1 is shared among Deliver1 and Source1.

- Make1 is the production function of Manufacturer 1 which transforms a quantity of Make1Products units in every round at a production cost of Make1Money (considered null in this paper).

Specifically, Make1 performs two actions in every round: (i) if the work-in-process inventory of Make1 is full with Make1Products items, then this content is moved into Deliver 1 to simulate the end of the transformation of these items, and (ii) whenever Source 1 contains more than Make1Products items, a new production batch is launched by moving a quantity of exactly Make1Products items from Source 1 into Make1. When Source 1 does not contain enough items, then nothing is moved, so that the work-in-process inventory Make 1 is either empty or full, but never half-full.

- Source 1 is similar to other inventories, that is, she holds products and bids in Market 12 in order to purchase the raw materials which will next be transformed by Make1.

RawMatProd1 in Figure 1(a) and RawMatProd2 in Figure 1(b) have two functions, which reflect EndCustomer0:

- Make $\{1,2\}$ produces Make $\{1,2\}$ Products $=+P>0$ units of food every round by adding them into the inventory Deliver $\{1,2\}$, and consumes Make $\{1,2\}$ Money $=-M<0$ units of money every round. If it cannot consume this quantity of money, it forgets this fact in the future (i.e., RawMatProd $\{1,2\}$ neither dies nor tries to consume more money in the future).

- Deliver $\{1,2\}$ bids in Market $\{01,12\}$ in order to keep its level Deliver $\{1,2\}$ Level at Deliver $\{1,2\}$ Target, and starts the simulation at level Deliver $\{1,2\}$ Ini.

The sequence of actions is as follows: (i) Delivers and Sources place their shout first; next (ii) Makes produce, and Market 01 is always invoked before Market12. In figure 1(b), this results in the sequence: (i) Source 0 and Deliver 1 place a shout in Market 01 (in random order, i.e. either Source 0 or Deliver 1 first), (ii) Market 01 is cleared, (iii) Source 1 and Deliver 2 place a shout in Market 12 (in any order), (iv) Market 12 is cleared, (v) Make0 is invoked, (vi) Make1 is called, (vii) Make2 is executed, and (i') another similar round starts by having Source 0 and Deliver 1 place a bid in Market01, etc.

\subsection{The Bidding Strategy from (Steiglitz et al., 1996)}

As just described, companies do not bid directly in auctions; this is the role of their Source and/or Deliver inventories. We now describe the bidding strategy they use. Because we use the bidding 
strategies proposed by Steiglitz et al. (1996), we will also use their terminology, and explain how we combine these strategies with the SCOR model presented in the previous section. With regard to terminology, the model in (Steiglitz et al., 1996) has the lowest possible number of goods to enable trade, that is, two goods, which are called "food" and "gold". In the remainder of the paper, we will call the first kind either "food", "good", "unit", "product" or "item", and the second type either "gold" or "money".

Next, JASA splits any bidding strategy into two parts, namely the valuation of the good and the bidding strategy itself. The valuation of the good is detailed in (Steiglitz et al., 1996, p. 5) as

$$
\operatorname{Valuation}(t, \bar{f}, \bar{g})=P(t-1) * B(\bar{f}, \bar{g}) \text {, }
$$

where:

- $P(t-1)$ is the price in the considered market in the previous round,

- $\bar{f}$ is the food inventory normalised by its target level,

- $\bar{g}$ represents the "gold inventory normalized by the current value of [the target level of the considered inventory]" (Steiglitz et al., 1996, p. 5),

- $B(\bar{f}, \bar{g})=\left[b_{0 \infty}-\left(b_{0 \infty}-b_{00}\right) e^{-\gamma \bar{g}}\right]^{(1-\bar{f})}$ with $\gamma=\ln \left(\frac{b_{0 \infty}-b_{00}}{b_{0 \infty}-b_{01}}\right) . B$ returns a value below one when the food inventory is above its target level, i.e. $B<1$ when $\bar{f}>1$, which makes the inventoryagent bid at a price lower than $P(t-1)$ in the hope to sell. $\bar{g}$ amplifies the value returned by $B$ depending on the richness of the agent, e.g., the richer a buyer, the more expensive she is ready to buy her food. Finally, the scaling parameters of $B$ are given in (Steiglitz and Shapiro, 1998, p. 43): $b_{00}=B(0,0)=4.0, b_{01}=B(0,1)=8.0$ and $b_{0 \infty}=B(0, \infty)=16.0$.

An important comment should be made about $B(\bar{f}, \bar{g})$. This function makes sellers decrease prices and buyers increase prices, which is of course not what we typically see in real life. The reason for this apparently strange design arises from the definitions of ask and bid shouts: (i) in bid shouts, buyers announce the maximum price they agree to spend on every item bought, (ii) while, in ask shouts, sellers announce the minimum price they want to be paid for every item sold. Next, any auctioneer clears the auction in more or less the same way by choosing a price higher than the price proposed in all matched ask shouts (and lower than any unmatched ask shout) and below the price proposed in all matched bid shouts. If we want matches to occur, then $B(\bar{f}, \bar{g})$ has to be defined in the counter-intuitive way it is now. If $B(\bar{f}, \bar{g})$ was designed according to intuition, then buyers would all propose a price below $P(t-1)$, sellers would propose a price above $P(t-1)$, and no shouts would ever be matched. ${ }^{9}$ We do not aim at addressing this question but only at adapting Steiglitz et al. (1996)'s model and stabilisation methods to supply chains. However, we will pay attention to this limitation when interpreting simulation runs, since it makes all suppliers try to decrease $P$, while this should be the role of their clients.

Finally, $\bar{f}, \bar{g}$ and $P$ need to be adapted to our model by replacing Valuation $(t, \bar{f}, \bar{g})$ by:

- Valuation $\left(t, \frac{\text { Source0Level }}{\text { Source0Target }}, \frac{\text { Money } 0}{\text { P01(t-1)*Source0Target }}\right)$

$$
=P 01(t-1) * B\left(\frac{\text { Source } 0 \text { Level }}{\text { Source0Target }}, \frac{\text { Money } 0}{P 01(t-1) * \text { Source0Target }}\right) \text { for Source } 0 \text {, }
$$

- Valuation $\left(t, \frac{\text { Deliver1Level }}{\text { Deliver1Target }}, \frac{\text { Money } 1}{P 01(t-1) * \text { Deliver1Target }}\right)$

$$
=P 01(t-1) * B\left(\frac{\text { Deliver1Level }}{\text { Deliver1Target }}, \frac{\text { Money } 1}{P 01(t-1) * \text { Deliver1Target }}\right) \text { for Deliver } 1 \text {. }
$$

$\bullet \ldots$

${ }^{9}$ How to design a valuation function is related to the origin of the value of goods, which is a large question (Dobb, 1981). For example, does value come (i) from the scarcity of goods, (ii) from the work necessary to produce goods, or (iii) from the utility drawn from using goods? $B(\bar{f}, \bar{g})$ implements the first of these three examples. 


\begin{tabular}{l|r} 
Asks & Bids \\
\hline (ask1) 1 unit at $£ 1.1$ & (bid1) 1 unit at $£ 2.2$ \\
(ask2) 1 unit at $£ 2.1$ & (bid2) 1 unit at $£ 1.2$
\end{tabular}

\begin{tabular}{l|r} 
Asks & Bids \\
\hline (ask1) 1 unit at $£ 1.1$ & $($ bid1 1$) 1$ units at $£ 2.2$ \\
(b) Example 2: askQuote $=P_{\text {bid1 }}=2.2$ and bidQuote $=$
\end{tabular}

(a) Example 1: askQuote $=P_{\text {ask } 2}=2.1$ and bidQuote $={ }_{P_{\text {ask } 1}=1.1}^{\text {(b) Exampla }}$

$P_{b i d 2}=1.2$

\begin{tabular}{l|r} 
Asks & Bids \\
\hline (ask1) 1 unit at $£ 1.1$ & (bid1) 2 units at $£ 2.2$ \\
(c) Example 3: askQuote $=$ bidQuote $=P_{\text {bid } 1}=2.2$
\end{tabular}

\begin{tabular}{l|r} 
Asks & Bids \\
\hline (ask1) 1 unit at $£ 1.1$ & $($ bid1 -1$) 1$ unit at $£ 2.2$ \\
& $($ bid1 -2$) 1$ unit at $£ 2.2$
\end{tabular}

(d) Another representation of Example 3: askQuote $=$ bidQuote $=P_{\text {bid } 1}=2.2$

Figure 2: Three examples of clearing by our JASA auctioneer.

- Valuation $\left(t, \frac{\text { Deliver2Level }}{\text { Deliver2Target }}, \frac{\text { Money } 2}{P 12(t-1) * \text { Deliver2Target }}\right)$
$\quad=P 12(t-1) * B\left(\frac{\text { Deliver } 2 \text { Level }}{\text { Deliver2Target }}, \frac{\text { Money }}{P 12(t-1) * \text { Deliver2Target }}\right)$ for Deliver 2.

The bidding strategy must calculate two values: the price and the quantity shouted. The price shouted is simply the true estimated Valuation $(t, \bar{f}, \bar{g})$, that is, the value of the good actually estimated by the agent without trying to pay less or be paid more. Next, the strategy calculates the quantity shouted in the following way:

- Essentially, the quantity bid is the one needed to keep $\bar{f}=1$, i.e., to keep the inventory at its target level. That is, a Source who wants to buy proposes the quantity (Source $\{0,1\}$ Level Source $\{0,1\}$ Target $)$, and a Deliver who wants to sell bids for (Deliver $\{1,2\}$ Target-Deliver 1,2 Level $)$ units.

Since Delivers are not allowed to buy, and Sources not to sell, the quantity returned by the previous two subtractions is always positive.

- However, if an inventory (i.e. a Source, since Delivers can only sell) wants to buy while it belongs to a company not rich enough (i.e., if the product of the price shouted by the quantity shouted is higher than the funds Money owned by the company), then she tries to buy the maximum quantity she can afford at the placed price Valuation $(t, \bar{f}, \bar{g})$, that is, the quantity placed is the largest integer which is less than or equal to Money/Valuation $(t, \bar{f}, \bar{g})$.

\subsection{The Clearing House Auctioneer Provided with JASA}

Besides the buyers and sellers, an institution is needed to match these two kinds of traders. In our model, this is a JASA auctioneer which calculates $P$ in every round. that (Steiglitz et al., 1996, p. 7) "no buyer [should] pay more than his bid" and "no seller [should] sell for less than his offer". We shall explain how our auctioneer is different from those used by Steiglitz et al. (1996), Steiglitz and Shapiro (1998) and Mizuta et al. (2003), and also the difference between the broadcast price $P$ and the clearing price $P$ Pl.

\section{Calculation of the Clearing Price $P c l$}

We now explain the operation of our auctioneer through the three examples in Figure 2. Example 1 in Figure 2(a) assumes four shouts, namely ask1, ask2, bid 1 and bid2, which are ordered in this figure in ascending order of price for asks, and by descending order of price for bids. With this order, matched shouts are at the top of the table, and unmatched shouts at the bottom. In fact, we can see in the first line of Figure 2(a) that ask 1 at the lowest sell price $£ 1.1$ can be matched with the bid1 at the highest buy 
price $£ 2.2$. On the contrary, in the second line, ask 2 with the second lowest sell price $£ 2.1$ cannot be matched with bid 2 at the second highest buy price $£ 1.2$. Since "no buyer [should] pay more than [her] bid" and "no seller [should] sell for less than his offer" (Steiglitz et al., 1996, p. 7), then the auctioneer should choose the clearing price $P c l$ so that two conditions are satisfied:

- $1.1 \leq P c l \leq 2.2$ (i.e. $P_{a s k 1} \leq P c l \leq P_{b i d 1}$ ) in order to match ask 1 with bid 1 in the first line, and

- $1.2<P c l<2.1$ (i.e., $P_{b i d 2}<P c l<P_{a s k 2}$ ) in order not to match ask 2 with bid2 in the second line.

Therefore, the auctioneer should choose $P c l$ so that $1.2<P c l<2.1$. Then, where exactly to place the clearing price $P c l$ ? JASA chooses $P c l$ by defining two numbers called askQuote and bidQuote (Phelps, 2007):

- askQuote is the price "buyers need to beat in order for their offers to get matched".

- "sellers need to ask less than bidQuote in order for their offers to get matched".

In Example 1, askQuote $=P_{a s k 2}=2.1$ because a new buyer would have to place a bid shout with a price above $P_{\text {ask } 2}$ in order to be matched with the unmatched ask2. Similarly, a new seller needs to ask less than bidQuote $=P_{b i d 2}=1.2$ to have her ask matched with the unmatched bid2. Pcl must necessarily be between askQuote and bidQuote to satisfy the two aforementioned conditions. In this paper, our auctioneer chooses $P c l$ so that $P c l=0.5 *$ askQuote $+0.5 *$ bidQuote $=1.65$. Finally, we call $P 01$ the broadcast price $P$ and $P c l 01$ the clearing price $P c l$ in Market 01 , and $P 12$ and $P c l 12$ their equivalents in Market 12.

Next, Examples 2 and 3 in Figures 2(b) and 2(c) illustrate a case often encountered later in this paper. In this case, there is only one buyer and one seller, their offers are matched, but the trader bidding for the highest quantity is favoured. To see this, Example 2 starts with a configuration in which both traders bid for the same quantity. It is easy to check that an additional bid shout should propose less than $£ 2.2$ in order to get matched with ask 1 , otherwise bid1 will win instead of the new bid shout; thus bidQuote $=P_{a s k 1}=2.2$. Similarly, an additional ask shout should propose more than $£ 1.1$ to get matched with bid1 at the place of ask1; thus askQuote $=P_{a s k 1}=1.1$. However, let us assume that bid 1 is not for 1 but for 2 units. This scenario is described in Figure 2(c), which may conveniently rewritten be as Figure 2(d) in which bid 1 is split into two shouts bid $1-1$ and bid $1-2$. As before, a new bid shout should propose less than $£ 2.2$ in order to get matched with ask1, otherwise bid 1 will win instead of the new bid shout; thus bidQuote $=P_{a s k 1}=2.2$. But the difference between Examples 2 and 3 is that a new ask shout should not propose more more than $P_{b i d 1}=£ 1.1$ anymore, but less than $P_{\text {bid1-2 }}=£ 2.2$, to get matched with bid1. As a consequence, bidQuote increases up to $£ 2.2$, bidQuote $=$ askQuote, and the buyer forces $P c l$ to move in the direction she wants. As explained before, the direction the buyer wants is to increase $P c l$, conversely to what intuition states. However, some of the price dynamics analysed in Sections 4 and 5 come from this method used to clear the auction. Specifically, we often obtain smooth price fluctuations when the Source buyer and the Deliver seller bid for the same quantity, then the price suddenly changes because a trader decreases or increases the quantity he or she proposes while the other trader keeps proposing the same quantity. Of course, other auctioneers/clearing algorithms may cause other price dynamics than this. Examples 3 illustrates a phenomenon encountered in the results in this paper when there is only one buyer and one seller in a market: in this scenario, we see that the trader proposing the highest quantity forces the auctioneer to choose his or her price, while the exchanged quantity is proposed by the other trader (in Example 3, the quantity exchanged is the one proposed in ask 1 , and the clearing price is the one asked in bid1).

\section{Definition of the Broadcast Price $P$}

Examples 1, 2 and 3 illustrate how $P c l$ is chosen by the auctioneer when at least one ask shout can be matched with at least one bid shout. If no matches are possible, then $\mathrm{Pcl}=0$. However, choosing 
$P=P c l=0$ is a problem for the bidding strategy used in this paper, because this makes all agents bid a price $P * B(\bar{f}, \bar{g})=0$. As a consequence, if $P(t)=0$ in some round $t$, then $P(t+k)=0$ in any round $(t+k), k>0$. In order to avoid this problem, we make a distinction between the actual clearing price $P c l$ and the price $P$ broadcast by the auctioneer. The three papers by Steiglitz do not make explicit this distinction between $P$ and $P c l$, but deal with $P c l=0$ in a way which can be described as (Steiglitz et al., 1996, p. 9):

$$
\begin{aligned}
P(t) & =P c l(t) \text { when } P c l \neq 0 ; \\
& =\text { askQuote }(t) \text { (i.e. the lowest ask price) when no agents buy; } \\
& =\text { bidQuote }(t) \text { (i.e. the highest bid price) when no agents sell; } \\
& =P(t-1) \text { when no agents trade. }
\end{aligned}
$$

Finally, we always start a simulation with $P(t-1)=P(-1)=1$ in all markets.

\subsection{Some Definitions}

\section{Balanced Supply Chain}

We call "balanced" a supply chain in which (i) the total transformation capacity of all Manufacturers is greater or equal to the total food consumption of all EndCustomers, and (ii) the total production capacity of all RawMatProds is equal to the total food consumption of all EndCustomers, and (iii) the total consumption of money of all RawMatProds is equal to the total production of money of all EndCustomers.

We start all our simulations with a balanced supply chain, i.e. (i) the production of food is balanced with its consumption: Make0Products $=-100$ and Make1Products $=100$, and (ii) the production of money is balanced with its consumption: Make0Money $=100$, Make1Money $=-100$ (simulations start with Money $\{0,1,2\}=1000)$. In addition, all inventory targets are the same throughout the paper with Source0Target $=$ Deliver1Target $=$ Source1Target $=$ Deliver2Target $=1500$, or, shortly, all InventoryTarget $=1500$.

\section{Equilibrium Price Peq}

The definition of the equilibrium price Peq needs to be adapted from that of (Steiglitz et al., 1996, p. 11), where it is the "price at which just enough agents produce food to satisfy the need of all nonspeculating agents." The idea of this definition is that agents start producing food (respectively, money) when $P>P e q$ (respectively, $P<P e q$ ) because it is more cost-efficient than producing money (respectively, food), which eventually triggers an excess (respectively, a deficit) of food and thus a decrease of $P$ below $P e q$ (respectively, an increase of $P$ above $P e q$ ).

Conversely to Steiglitz et al. (1996), the price has no influence on the production of food in our supply chain model. Specifically, $\mathrm{Peq}$ is the ratio of the production of money over the production of products when:

- Make1Money $=0$ (see Figure 1 for notations),

- the productions of products and money are balanced with their consumption, and

- there is only one company per level of the supply chain: only one EndCustomer 0 , one Manufacturer 1 and one RawMatProd $\{1,2\}$.

In this very particular case, $P e q$ is the same in the single market in Figure 1(a) and in the two markets in Figure 1(b): $P 01 e q=P 12 e q=P / M$. In this paper, we always use $M=P=100$ (e.g. Make0Products $=-100$ and Make0Money $=+100$ for every EndCustomer0), so that P01eq = $P 02 e q=1$. 
However, this paper also considers scenarios violating the third condition, that is, with several companies per level of the supply chain (see Subsections 4.2 and 5.3). In that case, Peq is much less trivial and will be studied in future work.

\section{The Single Market Scenario}

This section presents the price dynamics when some EndCustomer 0 s trade with some RawMatProd $1 \mathrm{~s}$ in Market01, which corresponds to Figure 1(a). Let us recall that we set all InventoryTargets to 1500 in this paper, but allow InventoryInis to change.

\subsection{Price Dynamics in the Single Market with Two Agents}

We start with only one EndCustomer 0 and one RawMatProd1, that is, the most simple supply chain possible with only two companies. Table 1 shows that initial conditions are very important in our supply chain model, because the dynamics of $P 01$ strongly depend on the initial value of the inventory levels. We now investigate this characteristic of our model and look for regularities in its behaviour. First of all, the most basic setting is in the center of table 1 when Source0Ini $=$ Source0Target $=1500$ and Deliver1Ini $=$ Deliver1Target $=1500$. With this configuration, P01 smoothly fluctuates around $P 01 e q=1$. We call B this pattern of smooth fluctuations because it is the border between the two other patterns in Table 1. As soon as one of both InventoryInis (i.e. either Source0Ini or Deliver1Ini) decreases (by one unit since it is the minimal change, because JASA uses integers to represent inventory levels), price fluctuations become chaotic; we call $\mathrm{C}$ this chaotic pattern. In stark contrast, as soon as either of both InventoryInis increases, we obtain Pattern A in which P01 falls to zero. To explain these three patterns, we should first notice that the initial difference ( $\sum$ InventoryTarget $-\sum$ InventoryIni) $>0$ remains during all the duration of a simulation because (i) the supply chain is balanced, and (ii) if an inventory Source0/Deliver 1 could not buy/sell all the units required to keep her/his level at InventoryTarget, then this is memorised in InventoryLevel $\neq$ InventoryTarget and bought/sold later on. With that in mind, we can find the following characteristics of the three patterns:

1. Pattern C:

(a) When Pattern C happens: Set $\left(\sum\right.$ InventoryTarget $-\sum$ InventoryIni $)<0$, e.g. Source0Ini $=$ 501 with Deliver1Ini $=2500$, and Source0Ini $=2500$ with Deliver1Ini $=501$ both incur Pattern C.

(b) How Pattern C happens: Pattern $\mathrm{C}$ is chaotic, that is, it looks like a random process, while it is not random at all since the simulation follows deterministic rules. ${ }^{10}$ Next, we can describe Pattern $\mathrm{C}$ as a succession of two types of periods:

- Period of increase of P01: In such periods, the auctioneer favours the buyer Source0 because she bids for more units than Deliver1. Deliver 1 bids for less units because he controls where the initial lack ( $\sum$ InventoryTarget $-\sum$ InventoryIni) is, and forces this lack to be with Source0. This control works this way: (i) if Deliver1 has this lack at the beginning of the simulation, then she places ask shouts for less units than his company RawMatProd 1 produces during the first rounds of the simulation, so that the lack is transfered to Source0, and (ii) if Source 0 has this lack at the beginning of the simulation, then she places bid shouts for more than she consumes, but she does not receive all these products because Deliver 1 only proposes what his company produces.

- Period of decrease of P01: In such periods, the auctioneer favours the seller Deliver1, because Source 0 is too poor ( $P 01$ is too high) to afford all the units, and bids thus for less units than Deliver1.

\footnotetext{
${ }^{10}$ The experiments reported in this paper use no pseudo-random number generators.
} 


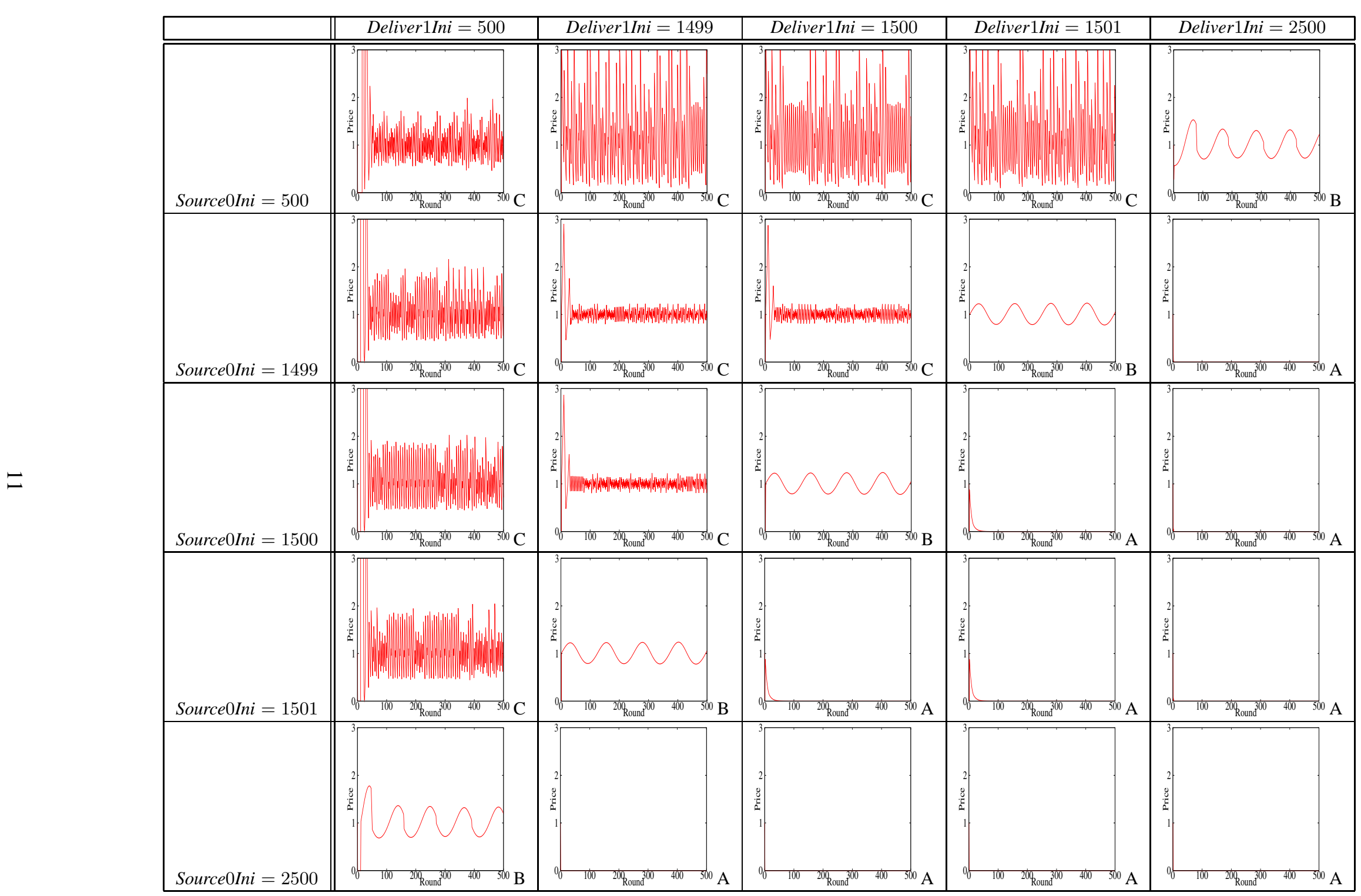

Table 1: Price dynamics in Market01 (with Source0Target $=$ Deliver1Target $=1500$ ). 


\begin{tabular}{|c|c|c|c|c|c|c|c|c|c|c|}
\hline \multirow[b]{3}{*}{ Round } & \multicolumn{8}{|c|}{ Start of round } & \multirow{2}{*}{\multicolumn{2}{|c|}{$\begin{array}{c}\text { End of Round } \\
\text { Auctioneer }\end{array}$}} \\
\hline & \multicolumn{4}{|c|}{ Source0 } & \multicolumn{4}{|c|}{ Deliver1 } & & \\
\hline & Funds & $\begin{array}{l}\text { Source0- } \\
\text { Level }\end{array}$ & $\begin{array}{c}\text { Quantity } \\
\text { bid }\end{array}$ & $\begin{array}{l}\text { Price } \\
\text { bid }\end{array}$ & Funds & $\begin{array}{l}\text { Deliver } 1- \\
\text { Level }\end{array}$ & $\begin{array}{c}\text { Quantity } \\
\text { asked }\end{array}$ & $\begin{array}{l}\text { Price } \\
\text { asked }\end{array}$ & $\begin{array}{c}\text { Quantity } \\
\text { exchanged }\end{array}$ & $P 01$ \\
\hline$\overline{00}$ & 1000 & $\overline{1500}$ & $\overline{0}$ & $\overline{00}$ & 1000 & 1499 & $\overline{00}$ & $\overline{00}$ & $\overline{0}$ & $\overline{1}$ \\
\hline 1 & 1100 & 1400 & 100 & 1.139 & 900 & 1599 & 99 & 0.882 & 99 & 1.139 \\
\hline 2 & 1087 & 1399 & 101 & 1.296 & 913 & 1600 & 100 & 1.007 & 100 & 1.296 \\
\hline 3 & 1058 & 1399 & 101 & 1.468 & 942 & 1600 & 100 & 1.148 & 100 & 1.468 \\
\hline 4 & 1011 & 1399 & 101 & 1.657 & 989 & 1600 & 100 & 1.302 & 100 & 1.657 \\
\hline 5 & 945 & 1399 & 101 & 1.863 & 1055 & 1600 & 100 & 1.472 & 100 & 1.863 \\
\hline 6 & 1141 & 1399 & 101 & 2.087 & 859 & 1600 & 100 & 1.656 & 100 & 2.087 \\
\hline 7 & 750 & 1399 & 101 & 2.329 & 1250 & 1600 & 100 & 1.856 & 100 & 2.329 \\
\hline 8 & 617 & 1399 & 101 & 2.590 & 1383 & 1600 & 100 & 2.072 & 100 & 2.590 \\
\hline 9 & 458 & 1399 & 101 & 2.868 & 1542 & 1600 & 100 & 2.304 & 100 & 2.868 \\
\hline 10 & 271 & 1399 & 85 & 3.164 & 1729 & 1600 & 100 & 2.551 & 85 & 2.551 \\
\hline 11 & 155 & 1384 & 54 & 2.850 & 1845 & 1615 & 115 & 2.220 & 54 & 2.220 \\
\hline 12 & 135 & 1338 & 51 & 2.592 & 1865 & 1661 & 161 & 1.818 & 51 & 1.818 \\
\hline 13 & 142 & 1289 & 63 & 2.228 & 1858 & 1710 & 210 & 1.387 & 63 & 1.387 \\
\hline 14 & 155 & 1252 & 87 & 1.769 & 1848 & 1747 & 247 & 0.993 & 87 & 0.993 \\
\hline 15 & 168 & 1239 & 130 & 1.292 & 1832 & 1760 & 260 & 0.682 & 130 & 0.682 \\
\hline 16 & 180 & 1269 & 206 & 0.869 & 1820 & 1730 & 230 & 0.478 & 206 & 0.478 \\
\hline 17 & 181 & 1375 & 125 & 0.548 & 1819 & 1624 & 124 & 0.390 & 124 & 0.548 \\
\hline
\end{tabular}

Table 2: Example of simulation trace of Pattern C (winning prices and quantities are in italics).

Since Source0 cannot buy all what EndCustomer 0 consumes, she lacks more than ( $\sum$ InventoryTarget $-\sum$ InventoryIni) units.

The system alternates between these two kinds of periods, depending on whether Source 0 has enough money to buy all that she consumes (increase of $P 01$ ), or not (decrease of P01). A consequence of this alternation is that the price $P 01$ does not fluctuate in a smooth way because it is chosen as being alternatively the price proposed either by the seller or by the buyer.

(c) Example of Pattern $C$ : Table 2 illustrates the two aforementioned types of periods: P01 increases from Rounds 0 to 10 , next decreases from 10 to 17, and increases from 17 on. Numbers in italics indicate the value chosen by the auctioneer. We can see the auctioneer selects (i) the price bid by the Source 0 buyer and the quantity asked by the Deliver 1 seller during the increase of $P 01$, and (ii) the other way around during the decrease of $P 01$. As noted in Example 3 in Figure 2(d), the trader proposing the highest quantity forces the auctioneer to use his or her price, while the exchanged quantity is the one proposed by the other trader. Regarding (ii), remember that, in the "period of decrease of P01", Source0 does not bid for all the units she needs because she is too poor to afford that quantity. Finally, we can also read in Table 2 that the initial conditions of the presented data are Source0Ini $=1500$ with Deliver1Ini $=1499$.

In summary, in Pattern C, the Source 0 buyer is always favoured (i.e. P01 is the price she proposes), except when she lacks of money in which case the Deliver 1 seller is favoured (i.e., P01 is his price). Switching between the prices proposed by Source 0 and Deliver 1 stabilises the price around P01eq because Source 0 increases $P 01$ as much as she can afford to, while Deliver 1 decreases $P 01$ until Source 0 can afford to buy all what she consumes. Switching between the prices proposed by these two traders also causes the brutality of the fluctuations of $P 01$.

\section{Pattern B:}

(a) When Pattern B happens: Set $\left(\sum\right.$ InventoryTarget $-\sum$ InventoryIni $)=0$, e.g. Source0Ini $=$ 
501 with Deliver1Ini $=2499$, and Source0Ini $=2499$ with Deliver1Ini $=501$ both incur Pattern B.

(b) How Pattern B happens: Pattern B corresponds to a border between Patterns A and C. Since JASA only allows for integer inventory levels, it is not possible to investigate what happens close to this border, i.e. when ( $\sum$ InventoryTarget $-\sum$ InventoryIni $) \approx 0$. As can be seen in Figure 1, Pattern B is made of cycles of slow increases of $P 01$, sometimes followed by sudden decreases of $P 01$, next always followed by slow decreases of $P 01$ :

- Period of slow increase of P01: In such periods, both Source0 and Deliver 1 bid for the same quantity (100 units), i.e., the excess in one inventory is equal to the lack in the other inventory. Since bid quantities are equal, Pcl01 is chosen by the auctioneer half-way between the price proposed by these two inventories, and, because Source 0 feels richer than Deliver 1 , the price proposed by Source 0 raises quicker than the price proposed by Deliver 1 decreases.

- Sudden decrease of P01: This is a short period (usually about five rounds) which does not happen with all initial conditions. In the simulation in which it occurs, it concludes a "period of slow increase of P01". Visually, this decrease corresponds to a shape different from a sine-like one. When this decrease occurs, it corresponds to the fact that Source 0 cannot bid for all the products she needs because $P 01$ is too high. As a consequence, the auctioneer uses the price proposed by Deliver 1 as $P$, while it was the price proposed by Source 0 in the "period of slow increase of $P 01$ ". As a consequence, the quantities bid by both inventories stop to be equal and the auctioneer chooses $P 01$ as the price proposed by Deliver1, while $P 01$ was half-way between the two proposed prices in the previous period. Such a choice makes so that $P 01$ stops to have the exponential shape of Function $B$ and has instead a sudden decrease.

- Period of slow decrease of P01: This period is the opposite of a "period of slow increase of P01", i.e., Deliver 1 feels richer than Source0 and makes thus the price decrease.

- Sudden increase of P01: We have never observed such an event, but it would correspond to a lack of products by Deliver 1 (which is the opposite of a "sudden decrease of $P 01$ " which corresponds to a lack of money by Source0).

(c) Example of Pattern B: Table 3 illustrates two of the three aforementioned types of periods: $P 01$ increases from Rounds 0 to 32, next decreases from 32 to 93, and increases from 93 on. The most noticeable thing in this table is that products do not seem to move because both inventories start and finish at the same level. For example, in every round, Source0 starts at 1400, consumes 100 units, purchases 100 units, and finishes at 1400. Next, there is no "Sudden decrease of $P 01$ ", and, therefore, $P 01$ is never chosen as the price proposed by either trader. In fact, $P 01$ is always chosen half-way between the two propositions, and only the difference of speed of variation between these two proposed prices explains the slow fluctuations of $P 01$. This difference of speed of variation is due to the function $B(\bar{f}, \bar{g})$ which depends on both the wealth $\bar{g}$ of the company and the inventory level $\bar{f}$, where only $\bar{g}$ changes while $\bar{f}=1$ all the time (indeed, an exception is possible: $\bar{f} \neq 1$ during a "Sudden decrease of $P 01 ")$.

Essentially, the smooth fluctuations of $P 01$ around P01eq in Pattern B are due to the fact that one inventory is richer (Source 0 during increases of P01, Deliver 1 during decreases) than the other one while both bid for the same quantity. There may be discontinuities of these smooth fluctuations; in the simulations in which they occur, such discontinuities correspond to a lack of money by the producer of money EndCustomer 0 which manages Source0.

\section{Pattern A:}




\begin{tabular}{|c|c|c|c|c|c|c|c|c|c|c|}
\hline \multirow[b]{3}{*}{ Round } & \multicolumn{8}{|c|}{ Start of round } & \multirow{2}{*}{\multicolumn{2}{|c|}{$\begin{array}{c}\text { End of Round } \\
\text { Auctioneer }\end{array}$}} \\
\hline & \multicolumn{4}{|c|}{ Source0 } & \multicolumn{4}{|c|}{ Deliver 1} & & \\
\hline & Funds & $\begin{array}{l}\text { Source } 0- \\
\text { Level }\end{array}$ & $\begin{array}{c}\text { Quantity } \\
\text { bid }\end{array}$ & $\begin{array}{c}\text { Price } \\
\text { bid }\end{array}$ & Funds & $\begin{array}{l}\text { Deliver } 1- \\
\text { Level }\end{array}$ & $\begin{array}{l}\text { Quantity } \\
\text { asked }\end{array}$ & $\begin{array}{l}\text { Price } \\
\text { asked }\end{array}$ & $\begin{array}{l}\text { Quantity } \\
\text { exchanged }\end{array}$ & $P 01$ \\
\hline$\overline{00}$ & $\overline{1000}$ & $\overline{1500}$ & $\overline{00}$ & $\overline{0}$ & 1000 & $\overline{1500}$ & $\overline{00}$ & $\overline{0}$ & $\overline{00}$ & $\overline{1} 1$ \\
\hline 1 & 1100 & 1400 & 100 & 1.139 & 900 & 1600 & 100 & 0.882 & 100 & 1.011 \\
\hline 2 & 1099 & 1400 & 100 & 1.151 & 901 & 1600 & 100 & 0.891 & 100 & 1.021 \\
\hline 3 & 1097 & 1400 & 100 & 1.163 & 903 & 1600 & 100 & 0.901 & 100 & 1.032 \\
\hline 4 & 1094 & 1400 & 100 & 1.175 & 906 & 1600 & 100 & 0.911 & 100 & 1.043 \\
\hline$\ldots$ & $\ldots$ & $\ldots$ & .. & $\ldots$ & $\ldots$ & . & . & $\cdots$ & $\cdots$ & $\cdots$ \\
\hline 30 & 696 & 1400 & 100 & 1.375 & 1304 & 1600 & 100 & 1.075 & 100 & 1.225 \\
\hline 31 & 673 & 1400 & 100 & 1.375 & 1326 & 1600 & 100 & 1.076 & 100 & 1.225 \\
\hline 32 & 651 & 1400 & 100 & 1.374 & 1349 & 1600 & 100 & 1.075 & 100 & 1.225 \\
\hline 33 & 628 & 1400 & 100 & 1.373 & 1372 & 1600 & 100 & 1.075 & 100 & 1.224 \\
\hline$\ldots$ & . & $\ldots$ & . & $\cdots$ & . & & & & & \\
\hline 91 & 658 & 1400 & 100 & 0.895 & 1342 & 1600 & 100 & 0.686 & 100 & 0.790 \\
\hline 92 & 679 & 1400 & 100 & 0.895 & 1321 & 1600 & 100 & 0.686 & 100 & 0.791 \\
\hline 93 & 699 & 1400 & 100 & 0.896 & 1301 & 1600 & 100 & 0.687 & 100 & 0.791 \\
\hline 94 & 720 & 1400 & 100 & 0.898 & 1280 & 1600 & 100 & 0.687 & 100 & 0.793 \\
\hline
\end{tabular}

Table 3: Example of simulation trace of Pattern B (winning quantities are in italic).

(a) When Pattern A happens: Set ( $\sum$ InventoryTarget $-\sum$ InventoryIni) $>0$, e.g. Source0Ini $=$ 499 with Deliver1Ini $=2500$, and Source0Ini $=2500$ with Deliver1Ini $=499$ both lead to Pattern A.

(b) How Pattern A happens: In all rounds, Deliver1 sells one unit more than Source0 buys, thus the auctioneer chooses the price bid by Deliver 1 as $P$. Since Deliver 1 tries to reduce the price in the hope to sell, then $P$ decreases. This behaviour is indeed the exact opposite to a "Period of increase of $P 01$ " in Pattern C.

$P 01$ never goes up because we never have the exact opposite of a "Period of decrease of $P 01$ " in Pattern C, which would be caused by a Deliver 1 with too few products (which is the opposite of "Source0 is too poor"). This seems to indicate that a fourth pattern looking like Pattern $\mathrm{C}$ is possible when InventoryTargets are set closer to zero.

Notice that a consequence of the decrease of $P 01$ to zero is that Deliver 1 is not able to acquire the money consumed by his company RawMatProd1, which quickly cannot have any of the gold units it is supposed to consume.

Finally, Pattern A looks very unrealistic because $P 01$ falls to zero only because of the initial levels of the inventories. Since this would not happen in real life, simulations in which Pattern A occurs should be disregarded. The problem with this pattern is that it seems not to be specific to our auctioneer or to the bidding strategy, that is, it cannot be avoided by fixing something in the code of the simulator. One solution to avoid Pattern A would be to introduce a bidding strategy which looks into the past.

(c) Example of Pattern A: Table 4 illustrates how P01 decreases forever.

In conclusion, the sign of ( $\sum$ InventoryTarget $-\sum$ InventoryIni) allows the determination of the pattern of the dynamics of $P 01$ when there is only one Source 0 trading with only one Deliver 1 . We call Rule 2 this comparison:

Rule 2 (temporary version): If one Source 0 buys in Market 01 and one Deliver 1 sells in this market, then:

- If ( $\sum$ InventoryTarget $-\sum$ InventoryIni $)<0$, then $P 01$ has a Pattern $\mathrm{C}$;

- If $\left(\sum\right.$ InventoryTarget $-\sum$ InventoryIni $)=0$, then $P 01$ has a Pattern B; 


\begin{tabular}{|c|c|c|c|c|c|c|c|c|c|c|}
\hline \multirow[b]{3}{*}{ Round } & \multicolumn{8}{|c|}{ Start of round } & \multirow{2}{*}{\multicolumn{2}{|c|}{$\begin{array}{c}\text { End of Round } \\
\text { Auctioneer }\end{array}$}} \\
\hline & \multicolumn{4}{|c|}{ Source0 } & \multicolumn{4}{|c|}{ Deliver 1} & & \\
\hline & Funds & $\begin{array}{l}\text { Source0- } \\
\text { Level }\end{array}$ & $\begin{array}{c}\text { Quantity } \\
\text { bid }\end{array}$ & $\begin{array}{c}\text { Price } \\
\text { bid }\end{array}$ & Funds & $\begin{array}{l}\text { Deliver } 1- \\
\text { Level }\end{array}$ & $\begin{array}{c}\text { Quantity } \\
\text { asked }\end{array}$ & $\begin{array}{l}\text { Price } \\
\text { asked }\end{array}$ & $\begin{array}{c}\text { Quantity } \\
\text { exchanged }\end{array}$ & $P 01$ \\
\hline 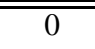 & 1000 & 1500 & 0 & 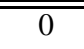 & 1000 & 1501 & $\overline{00}$ & $\overline{0}$ & 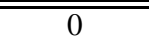 & $\overline{1} 1$ \\
\hline 1 & 1100 & 1400 & 100 & 1.138 & 900 & 1601 & 101 & 0.880 & 100 & 0.880 \\
\hline 2 & 1112 & 1400 & 100 & 1.006 & 888 & 1601 & 101 & 0.773 & 100 & 0.773 \\
\hline 3 & 1134 & 1400 & 100 & 0.887 & 865 & 1601 & 101 & 0.677 & 100 & 0.677 \\
\hline 4 & 1167 & 1400 & 100 & 0.780 & 833 & 1601 & 101 & 0.592 & 100 & 0.592 \\
\hline$\ldots$ & $\ldots$ & $\ldots$ & $\ldots$ & $\ldots$ & $\ldots$ & $\ldots$ & $\ldots$ & $\ldots$ & $\ldots$ & $\ldots$ \\
\hline
\end{tabular}

Table 4: Example of simulation trace of Pattern A (winning prices and quantities are in italic).

- If $\left(\sum\right.$ InventoryTarget $-\sum$ InventoryIni $)>0$, then $P 01$ has a Pattern A.

The next subsection introduces Rule 1 to apply before Rule 2 , and slightly modifies Rule 2 in order to accomodate with the scenario in which more than one Source 0 and more than one Deliver 1 trade in Market01.

\subsection{Price Dynamics in the Single Market with Many Agents}

We now study what happens when there are several Source0s buying from several Deliver1s. As in the rest of this paper, all InventoryTargets are set to 1500 in this subsection. Since we noticed in the previous subsection that the sign of ( $\sum$ InventoryTarget $-\sum$ InventoryIni) seems to be more important than the actual value of the different InventoryTargets and InventoryInis (Rule 2), the cases InventoryIni $=500$ and InventoryIni $=2500$ are not taken into account in this subsection. Table 5 proposes a small sample of all the possible combinations of several Source0s trading with several Deliver1s. First of all, we obtain the same three patterns A, B and C of $P 01$ as in Figure 1.

Next, Table 5 should be understood as follows. The first line presents two configurations: the left one is "111 111" in which three Source0s (starting at levels 1499, 1500 and 1501) buy from three Deliver1s (starting at levels 1499, 1500 and 1501), which incurs Pattern B, while, the right configuration of the first line is "211 111" in which four Source0s (starting at levels 1499, 1499, 1500 and 1501) buy from three Deliver1s (starting at levels 1499, 1500 and 1501) and a Pattern C is obtained.

We first check that Rule 2 is not enough to predict what pattern will happen when there are many agents. In fact, ( $\sum$ InventoryTarget $)-\left(\sum\right.$ InventoryIni) may be rewritten as $\left(\sum_{i=0}^{\# \text { Source } 0}\right.$ Sour-

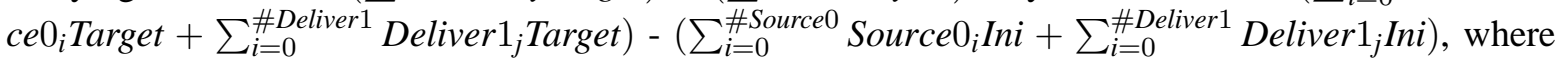
\#Source 0 is the number of Source0s. The entry "111 121" (left column in third line) provides us with an example showing that this reading of Rule 2 does not work: Table 5 reports that the simulation exhibits Pattern A, while Rule 2 would propose Pattern B:

- $\sum_{i=0}^{\# \text { Source } 0}$ Source $0_{i}$ Target $=1500 * 3=4500$,

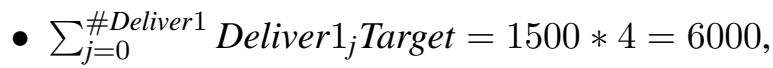

- $\sum_{i=0}^{\# \text { Source } 0}$ Source $_{i}$ Ini $=1499+1500+1501=4500$,

- $\sum_{j=0}^{\# \text { Deliver } 1}$ Deliver $_{j}$ Ini $=1499+1500+1500+1501=6000$,

- $\Rightarrow\left(\sum\right.$ InventoryTarget $)-\left(\sum\right.$ InventoryIni $)=(4500+6000)-(4500+6000)=0 \Rightarrow$ Pattern B.

This example demonstrates that adding one Deliver $1_{j}$ starting with Deliver $1_{j}$ In $i=$ Deliver $_{j}$ Target $_{\text {does }}$ not change the sign of ( $\sum$ InventoryTarget $-\sum$ InventoryIni), while this Deliver $1_{j}$ proposes products to sell in Market01 and impacts thus on P01. 


\begin{tabular}{|c|c|c|c|c|c|c|c|c|c|c|c|c|c|c|c|}
\hline 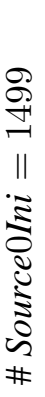 & 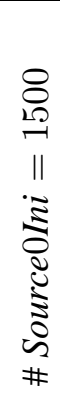 & 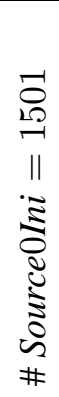 & 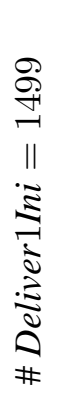 & 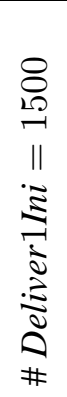 & 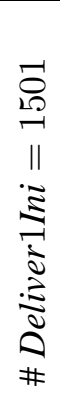 & 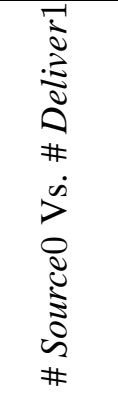 & 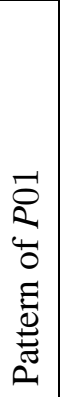 & 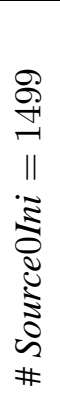 & 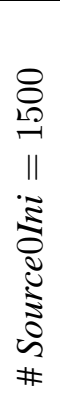 & 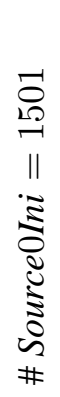 & 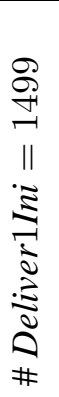 & 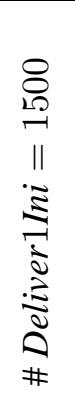 & 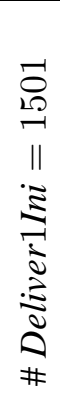 & 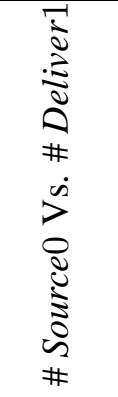 & 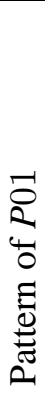 \\
\hline $\bar{~} 1$ & 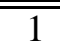 & $\bar{~} 1$ & $\bar{~} 1$ & 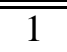 & $\overline{c 1}$ & $3=3$ & $\overline{\mathrm{B}}$ & 2 & $\overline{c 1}$ & $\overline{c 1}$ & $\bar{~} 1$ & $\bar{~} 1$ & $\bar{~} 1$ & 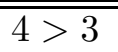 & $\overline{\mathrm{C}}$ \\
\hline 1 & 1 & 1 & 1 & 1 & 2 & $3<4$ & A & 2 & 1 & 1 & 1 & 1 & 2 & $4=4$ & B \\
\hline 1 & 1 & 1 & 1 & 2 & 1 & $3<4$ & $\mathrm{~A}$ & 2 & 1 & 1 & 1 & 2 & 1 & $4=4$ & $\mathrm{C}$ \\
\hline 1 & 1 & 1 & 1 & 2 & 2 & $3<5$ & A & 2 & 1 & 1 & 1 & 2 & 2 & $4<5$ & A \\
\hline 1 & 1 & 1 & 2 & 1 & 1 & $3<4$ & $\mathrm{~A}$ & 2 & 1 & 1 & 2 & 1 & 1 & $4=4$ & $\mathrm{C}$ \\
\hline 1 & 1 & 1 & 2 & 1 & 2 & $3<5$ & A & 2 & 1 & 1 & 2 & 1 & 2 & $4<5$ & A \\
\hline 1 & 1 & 1 & 2 & 2 & 1 & $3<5$ & A & 2 & 1 & 1 & 2 & 2 & 1 & $4<5$ & A \\
\hline 1 & 1 & 1 & 2 & 2 & 2 & $3<6$ & A & 2 & 1 & 1 & 2 & 2 & 2 & $4<6$ & A \\
\hline 1 & 1 & 2 & 1 & 1 & 1 & $4>3$ & $\mathrm{C}$ & 2 & 1 & 2 & 1 & 1 & 1 & $5>3$ & $\mathrm{C}$ \\
\hline 1 & 1 & 2 & 1 & 1 & 2 & $4=4$ & A & 2 & 1 & 2 & 1 & 1 & 2 & $5>4$ & $\mathrm{C}$ \\
\hline 1 & 1 & 2 & 1 & 2 & 1 & $4=4$ & A & 2 & 1 & 2 & 1 & 2 & 1 & $5>4$ & $\mathrm{C}$ \\
\hline 1 & 1 & 2 & 1 & 2 & 2 & $4<5$ & $\mathrm{~A}$ & 2 & 1 & 2 & 1 & 2 & 2 & $5=5$ & A \\
\hline 1 & 1 & 2 & 2 & 1 & 1 & $4=4$ & B & 2 & 1 & 2 & 2 & 1 & 1 & $5>4$ & $\mathrm{C}$ \\
\hline 1 & 1 & 2 & 2 & 1 & 2 & $4<5$ & $\mathrm{~A}$ & 2 & 1 & 2 & 2 & 1 & 2 & $5=5$ & B \\
\hline 1 & 1 & 2 & 2 & 2 & 1 & $4<5$ & A & 2 & 1 & 2 & 2 & 2 & 1 & $5=5$ & $\mathrm{C}$ \\
\hline 1 & 1 & 2 & 2 & 2 & 2 & $4<6$ & A & 2 & 1 & 2 & 2 & 2 & 2 & $5<6$ & A \\
\hline 1 & 2 & 1 & 1 & 1 & 1 & $4>3$ & $\mathrm{C}$ & 2 & 2 & 1 & 1 & 1 & 1 & $5>3$ & $\bar{C}$ \\
\hline 1 & 2 & 1 & 1 & 1 & 2 & $4=4$ & A & 2 & 2 & 1 & 1 & 1 & 2 & $5>4$ & $\mathrm{C}$ \\
\hline 1 & 2 & 1 & 1 & 2 & 1 & $4=4$ & B & 2 & 2 & 1 & 1 & 2 & 1 & $5>4$ & $\mathrm{C}$ \\
\hline 1 & 2 & 1 & 1 & 2 & 2 & $4<5$ & A & 2 & 2 & 1 & 1 & 2 & 2 & $5=5$ & B \\
\hline 1 & 2 & 1 & 2 & 1 & 1 & $4=4$ & $\mathrm{C}$ & 2 & 2 & 1 & 2 & 1 & 1 & $5>4$ & $\mathrm{C}$ \\
\hline 1 & 2 & 1 & 2 & 1 & 2 & $4<5$ & A & 2 & 2 & 1 & 2 & 1 & 2 & $5=5$ & $\mathrm{C}$ \\
\hline 1 & 2 & 1 & 2 & 2 & 1 & $4<5$ & $\mathrm{~A}$ & 2 & 2 & 1 & 2 & 2 & 1 & $5=5$ & $\mathrm{C}$ \\
\hline 1 & 2 & 1 & 2 & 2 & 2 & $4<6$ & A & 2 & 2 & 1 & 2 & 2 & 2 & $5<6$ & A \\
\hline 1 & 2 & 2 & 1 & 1 & 1 & $5>3$ & $\mathrm{C}$ & 2 & 2 & 2 & 1 & 1 & 1 & $6>3$ & $\bar{C}$ \\
\hline 1 & 2 & 2 & 1 & 1 & 2 & $5>4$ & $\mathrm{C}$ & 2 & 2 & 2 & 1 & 1 & 2 & $6>4$ & $\mathrm{C}$ \\
\hline 1 & 2 & 2 & 1 & 2 & 1 & $5>4$ & $\mathrm{C}$ & 2 & 2 & 2 & 1 & 2 & 1 & $6>4$ & $\mathrm{C}$ \\
\hline 1 & 2 & 2 & 1 & 2 & 2 & $5=5$ & A & 2 & 2 & 2 & 1 & 2 & 2 & $6>5$ & $\mathrm{C}$ \\
\hline 1 & 2 & 2 & 2 & 1 & 1 & $5>4$ & $\mathrm{C}$ & 2 & 2 & 2 & 2 & 1 & 1 & $6>4$ & $\mathrm{C}$ \\
\hline 1 & 2 & 2 & 2 & 1 & 2 & $5=5$ & A & 2 & 2 & 2 & 2 & 1 & 2 & $6>5$ & $\mathrm{C}$ \\
\hline 1 & 2 & 2 & 2 & 2 & 1 & $5=5$ & B & 2 & 2 & 2 & 2 & 2 & 1 & $6>5$ & $\mathrm{C}$ \\
\hline 1 & 2 & 2 & 2 & 2 & 2 & $5<6$ & A & 2 & 2 & 2 & 2 & 2 & 2 & $6=6$ & B \\
\hline
\end{tabular}

Table 5: Pattern of the dynamics of $P 01$ when there are 3, 4, 5 or 6 Source 0 s trading with 3, 4, 5 or 6 Deliver1s. 
Therefore, Rule 2 is not enough because the relative numbers of sellers and buyers should also be taken into account. That's why Table 5 presents the number \#Source 0 of buyers and \#Deliver 1 of sellers. With these notations, the results in Table 5 seem to indicate that the three patterns A, B and C of $P 01$ have the following characteristics:

\section{Pattern $C$ :}

(a) When Pattern C happens:

- Either $(\#$ Source $0-\#$ Deliver 1$)=0$ and $\left(\sum\right.$ InventoryTarget $-\sum$ InventoryIni $)<0$, - Or (\#Source 0 - \#Deliver 1$)>0$.

(b) How Pattern C happens: The first condition is very similar to the previous subsection, that is, the case $(\#$ Source $0=\#$ Deliver $1=1)$ in the previous subsection resembles the case $(\#$ Source $0=\#$ Deliver $1>1)$. Specifically, we can see these initial conditions as setting a system with \#Source $0=$ \#Deliver 1 auctions running in parallel, where every auction has one Source 0 matched with one Deliver 1 (the matching is different in every round), and where Deliver1s collectively force Source 0 s to keep or receive the initial lack of products ( $\sum$ InventoryTarget $-\sum$ InventoryIni) at the beginning of the simulation. In other words, we observe the same two kinds of periods as for Pattern $\mathrm{C}$ in the previous subsection.

The second condition (\#Source 0 - \#Deliver $1>0$ ) is also quite similar to what happens in the previous subsection. More precisely, there are now more Source0s than Deliver1s which means that more products are consumed than produced. This disbalance leads to the same two kinds of periods:

- Periods of decrease of P01: These periods are as in the previous subsection, that is, Source0s are too poor to afford all what they consume because $P 01$ is too high. As a consequence, the total quantity ordered by Source 0 s is lower than the total quantity ordered by Deliver1, which causes one of the prices proposed by a Deliver 1 to be chosen as $P 01$.

- Periods of increase of P01: Basically, the total quantity consumed by buyers is greater than the total quantity produced by sellers, and thus, the total quantity to buy should be greater than the total quantity for sale. However, we have just seen that this does not work this way when $P 01$ is too high. This problem of wealth of the buyers does not apply (or, at least, is is less acute) during a period of increase of $P 01$. As a consequence, buyers now bid for a quantity higher than what is proposed by sellers.

(c) Example of Pattern C: Figures 3 and 4 illustrate these two types of periods:

- Periods of decrease of P01: Figure 3 illustrates this "period of decrease of P01" with the first round in which $P 01$ decreases (round 8) when there are four Source0s (starting with levels 1499, 1499, 1500 and 1501) and three Deliver 1 (starting at levels 1499, 1500 and 1501). Figure 3(a) presents the quantities and prices bid by the four Source0s and asked by the three Deliver1s. As in the examples in Figure 2, asks are written in ascending order of price, and bids in descending order of price. Figure 3(b) presents how the auctioneer splits these shouts. For example, ask 1 is split into ask $1-1$ and ask $1-2$ so that ask $1-1$ can be matched with bid 4 and ask $1-2$ with the part bid $3-1$ of bid3. With this representation, we can see that any new ask must be below $P_{a s k 3-2}$ to get matched with bid1, i.e. to beat ask3, thus bidQuote $=P_{a s k 3-2}$, and any new bid must be above $P_{a s k 3-2}$ to afford some of the 69 units of ask3-2, thus askQuote $=$ $P_{\text {ask3-2. }}$.

This example illustrates how sellers are collectively favoured by the auctioneer because they sell a total quantity higher than the total demand. Notice that all the prices asked may be matched by all the prices bid by definition of Valuation $(t, \bar{f}, \bar{g})$, and, therefore, 


\begin{tabular}{l|r} 
Asks & Bids \\
\hline (ask1) 100 units at $£ 4.85256341$ & (bid4) 91 units at $£ 7.278684$ \\
(ask2) 100 units at $£ 4.85259734$ & (bid3) 30 units at $£ 7.094054$ \\
(ask3) 100 units at $£ 4.85263601$ & (bid2) 30 units at $£ 6.631892$ \\
& (bid1) 80 units at $£ 4.852597$
\end{tabular}

(a) Ask and bid shouts.

\begin{tabular}{l|r} 
Asks & Bids \\
\hline (ask $1-1) 91$ units at $£ 4.85256341$ & (bid4) 91 units at $£ 7.278684$ \\
(ask $1-2) 09$ units at $£ 4.85256341$ & $($ bid $3-1) 09$ units at $£ 7.094054$ \\
(ask $2-1) 21$ units at $£ 4.85259734$ & $($ bid $3-2) 21$ units at $£ 7.094054$ \\
(ask2 - 2) 30 units at $£ 4.85259734$ & (bid2) 30 units at $£ 6.631892$ \\
(ask2 - 3) 49 units at $£ 4.85259734$ & $($ bid $1-1) 49$ units at $£ 4.852597$ \\
(ask $3-1) 31$ units at $£ 4.85263601$ & $($ bid $1-2) 31$ units at $£ 4.852597$ \\
(ask3 - 2) 69 units at $£ 4.85263601$ &
\end{tabular}

(b) Transformation of asks and bids shouts to see that askQuote $=$ bidQuote $=P_{a s k 3-2}=$ 4.85263601 in Figure 3(a).

Figure 3: Example of decrease of $P 01$ in Pattern C.

the only way to influence $P 01$ is to propose more products, as done here by the sellers. In fact, the buyers would like to bid for the same quantity as what is proposed by the sellers, but are too poor to afford this quantity. As a consequence, the price proposed by one of these sellers (here, $\left.P_{a s k 3-2}\right)$ is used as $P 01$, and since sellers always try to decrease the price, then $P 01(t)<P 01(t-1)$.

- Periods of increase of P01: Table 4 illustrates a round during a period of increase of $P 01$. The round considered is the fifteenth of the same simulation as Figure 3, which corresponds to the first round of the second period of increase in this simulation. More precisely, Figure 4(a) presents the shouts placed by the seven traders, and Table 4(b) how we can split these shouts to make askQuote and bidQuote obvious. The main thing to notice is that $P 01$ is now necessarily one of the $P_{b i d}$ s because buyers bid for a higher quantity, while it was one of the $P_{a s k}$ in Figure 3.

Shortly, $P 01$ suddenly "jumps", as in the Pattern C in the previous subsection, from one of the $P_{a s k} \mathrm{~s}$ to one of the $P_{b i d} \mathrm{~s}$ when we change of period, which explains why $P 01$ does not fluctuate smoothly. As a conclusion about Pattern A, we can say that this pattern occurs for same reasons when there is only one trader per level of the supply chain, and where there are more than one trader.

\section{Pattern B:}

(a) When Pattern B happens:

- Only when $(\#$ Source $0-\#$ Deliver 1$)=0$ and $\left(\sum\right.$ InventoryTarget $-\sum$ InventoryIni $)=$ 0 .

(b) How Pattern B happens: As with Pattern C, the case (\#Source $0=$ \#Deliver $1=1)$ of Pattern $\mathrm{B}$ resembles the case $(\#$ Source $0=\#$ Deliver $1>1)$. Again, everything happens as if $\#$ Source $0=\#$ Deliver 1 simulations were carried out in parallel. In the first few rounds, traders with an excess (respectively, a lack) products bids for more (respectively, for less), and are able to transfer this excess (respectively, lack) to another inventory when this second inventory has a lack (respectively, an excess). If this transfer does not occur or is not completed in a round, it may take place in the next round, so that, all inventories eventually 


\begin{tabular}{l|r} 
Asks & Bids \\
\hline (ask1) 229 units at $£ 0.36408550$ & (bid4) 229 units at $£ 1.04207499$ \\
(ask2) 216 units at $£ 0.37159512$ & (bid3) 272 units at $£ 0.95046649$ \\
(ask3) 100 units at $£ 0.45293937$ & (bid2) 280 units at $£ 0.93427686$ \\
& (bid1) 283 units at $£ 0.91019291$
\end{tabular}

(a) Ask and bid shouts.

\begin{tabular}{l|r} 
Asks & Bids \\
\hline (ask1) 229 units at $£ 0.36408550$ & $($ bid $4-1) 263$ units at $£ 1.04207499$ \\
$(a s k 2-1) 34$ units at $£ 0.37159512$ & $($ bid $4-2) 34$ units at $£ 1.04207499$ \\
$(a s k 2-2) 182$ units at $£ 0.37159512$ & $($ bid $3-1) 182$ units at $£ 0.95046649$ \\
$(a s k 3-1) 90$ units at $£ 0.45293937$ & $($ bid $3-2) 90$ units at $£ 0.95046649$ \\
$(a s k 3-2) 10$ units at $£ 0.45293937$ & $($ bid $2-1) 90$ units at $£ 0.93427686$ \\
& $($ bid $2-2) 190$ units at $£ 0.93427686$ \\
& (bid1) 283 units at $£ 0.91019291$ \\
(b) Transformation of asks and bids shouts to see that askQuote = bidQuote $=P_{\text {bid2 }}=$ \\
0.93427686 in Figure $4($ a).
\end{tabular}

Figure 4: Example of increase of $P 01$ in Pattern C.

have their level at their InventoryTarget. Next, in every round after this equilibration period, every Source 0 is matched with a Deliver 1 and the same exchange takes place in each pair Source $0 /$ Deliver 1 as in the previous subsection.

In a few words, Pattern B happens again because buyers are alternatively richer then poorer than sellers.

Notice that the conditions incurring Pattern B are the most intuitive way to set a simulation and this pattern will thus occur quite often, even though these conditions are very particular.

\section{Pattern A:}

(a) When Pattern A happens:

- Either $(\#$ Source $0-\#$ Deliver 1$)=0$ and $\left(\sum\right.$ InventoryTarget $-\sum$ InventoryIni $)>0$, - Or $(\#$ Source0 - \#Deliver 1$)<0$.

(b) How Pattern A happens: Again, the case $(\#$ Source $0=\#$ Deliver $1=1)$ of Pattern A resembles the case $(\#$ Source $0=\#$ Deliver $1>1)$, in which $P 01$ falls to zero because the sellers (instead of the single seller) are favoured by the auctioneer due to the fact they sell more than the buyers.

In conclusion, the sign of (\#Source 0 - \#Deliver 1$)$ allows the determination of the pattern of the dynamics of $P 01$ when there are several Source0s trading with several Deliver1s. The reasons for this are almost the same as in the previous subsection. We call Rule 1 this comparison:

Rule 1: If some Source0s buy in Market01, and some Deliver 1 sell in this market, then:

- If (\#Source $0-\#$ Deliver 1$)>0$, then P01 has a Pattern C;

- If $(\#$ Source $0-\#$ Deliver 1$)=0$, then apply Rule 2;

- If $(\#$ Source 0 - \#Deliver 1$)<0$, then P01 has a Pattern A.

In order to be used with Rule 1, Rule 2 needs to be slightly rewritten as: 
Rule 2: If as many Source0s buy in Market01 as many Deliver1s sell in this market, then:

- If ( $\sum$ InventoryTarget $-\sum$ InventoryIni $)<0$, then P01 has a Pattern $\mathrm{C}$;

- If $\left(\sum\right.$ InventoryTarget $-\sum$ InventoryIni $)=0$, then $P 01$ has a Pattern B;

- If $\left(\sum\right.$ InventoryTarget $-\sum$ InventoryIni $)>0$, then P01 has a Pattern A.

\section{The Two Market Scenario}

We now detail the price dynamics of $P 01$ and $P 02$ in the two auctions of the supply chain in Figure 1(b). For that purpose, we first sketch the changes in the considered scenario in comparison with the previous section. Next, we present the price dynamics when there is the minimal number of agents, i.e. one agent at each level of the supply chain. Finally, we outline how we expect to study scenarios with more agents in the future.

\subsection{Presentation of the Two Markets and the Three Agents}

In comparison with the previous section, we consider the two auctions Market 01 and Market 12 instead of only Market01, which leads us to add Manufacturer1, and to change the name of the raw material supplier from RawMatProd1 to RawMatProd2.

\subsection{Price Dynamics in the Two Markets with Three Agents}

The simulation of two auctions with one seller and one buyer per auction shows the same Patterns A, $\mathrm{B}$ and $\mathrm{C}$ as in the previous section (see Appendix A for details). As a consequence, we can summarise the dynamics of $P 01$ and $P 12$ with Table 6 . In fact, it is even possible to generate Table 6 from (any version of) Rule 2 (Rule 1 does not apply here because there are not more than one buyer and one seller per market). In order to illustrate this, let us consider the case Source0Ini $=$ Deliver1Ini $=$ Source1Ini $=1501$ and Deliver 2 Ini $=1499$ (i.e. the lower right entry in Table 6, and the bottom left entry in Table 9) which has Pattern A twice. Market01 has Pattern A according to Rule 2 because Source0Ini + Deliver1Ini $=1501+1501$ is greater than Source0Target + Deliver 1 Target $=1500+1500$. But there seems to be a problem with Market 12 which should have Pattern B according to Rule 2 (because Source1Ini + Deliver2Init $=1501+1499$ is equal to Source1Target + Deliver2Target $=$ $1500+1500)$, but is replaced by Pattern A in Table 6 .

When the application of Rule 2 does not match the results obtained by simulation, the pattern obtained by simulation is written in italics in Tables 6 (as well as Tables 7, 8 and 9). We can see that italics is only for "A"s in Market12. The explanation for this is that a Pattern A in Market01 makes so that Manufacturer 1 is not able to attract money from the producer of money (i.e. EndCustomer 0 ) because the price falls to zero. As a consequence, Manufacturer 1 cannot send this money into Market 12 , and, therefore, $P 12$ cannot have its normal pattern due to the fact that Manufacturer 1 becomes poorer and poorer. This explains why the differences between the application of Rule 2 and actual simulation results only (i) affect Market 12, (ii) deal with Pattern A in Market 01 and (iii) incur Pattern A in Market 12 but never Patterns B or C. Eventually, we can infer Rule 3 from Table 6:

Rule 3: If a market (Market01 in our case) has Pattern A, then a market further from EndCustomers (Market 12 in our case) will also have Pattern A.

Therefore, Rule 2 should be applied first, next Rule 3. As described in the next subsection when there are several buyers and sellers in some market, whether Rule 1 should be applied before Rule 2 is left for future work. 


\begin{tabular}{|c|c|c|c|c|c|c|c|c|c|c|c|c|c|c|c|c|c|c|c|}
\hline \multirow{4}{*}{ 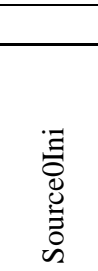 } & \multirow{4}{*}{ 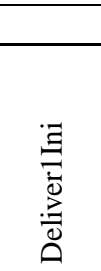 } & \multicolumn{6}{|c|}{ Source1Ini=1499 } & \multicolumn{6}{|c|}{ Source1Ini=1500 } & \multicolumn{6}{|c|}{ Source1Ini=1501 } \\
\hline & & \multicolumn{6}{|c|}{ Deliver2Ini } & \multicolumn{6}{|c|}{ Deliver2Ini } & \multicolumn{6}{|c|}{ Deliver2Ini } \\
\hline & & \multicolumn{2}{|c|}{$=1499$} & \multicolumn{2}{|c|}{$=1500$} & \multicolumn{2}{|c|}{$=1501$} & \multicolumn{2}{|c|}{$=1499$} & \multicolumn{2}{|c|}{$=1500$} & \multicolumn{2}{|c|}{$=1501$} & \multicolumn{2}{|c|}{$=1499$} & \multicolumn{2}{|c|}{$=1500$} & \multicolumn{2}{|c|}{$=1501$} \\
\hline & & $P 01$ & $P 12$ & $P 01$ & $P 12$ & $P 01$ & $P 12$ & $P 01$ & $P 12$ & $P 01$ & $P 12$ & $P 01$ & $P 12$ & $P 01$ & $P 12$ & $P 01$ & $P 12$ & $P 01$ & $P 12$ \\
\hline \multirow{3}{*}{$=1499$} & $=1499$ & $\mathrm{C}$ & $\mathrm{C}$ & $\mathrm{C}$ & $\mathrm{C}$ & $\mathrm{C}$ & B & $\mathrm{C}$ & $\mathrm{C}$ & $\mathrm{C}$ & $\mathrm{B}$ & $\mathrm{C}$ & $\mathrm{A}$ & $\mathrm{C}$ & $\mathrm{B}$ & $\mathrm{C}$ & $\bar{A}$ & $\mathrm{C}$ & $\mathrm{A}$ \\
\hline & $=1500$ & $\mathrm{C}$ & $\mathrm{C}$ & $\mathrm{C}$ & $\mathrm{C}$ & $\mathrm{C}$ & B & $\mathrm{C}$ & $\mathrm{C}$ & $\mathrm{C}$ & B & $\mathrm{C}$ & A & $\mathrm{C}$ & B & $\mathrm{C}$ & A & $\mathrm{C}$ & A \\
\hline & $=1501$ & B & $\mathrm{C}$ & $\mathrm{B}$ & $\mathrm{C}$ & $\mathrm{B}$ & B & B & $\mathrm{C}$ & B & B & $\mathrm{B}$ & A & B & B & B & A & B & A \\
\hline \multirow{3}{*}{$=1500$} & $=1499$ & $\mathrm{C}$ & $\mathrm{C}$ & $\mathrm{C}$ & $\mathrm{C}$ & $\mathrm{C}$ & B & $\mathrm{C}$ & $\mathrm{C}$ & $\bar{C}$ & B & $\mathrm{C}$ & $\mathrm{A}$ & $\mathrm{C}$ & B & $\mathrm{C}$ & $\mathrm{A}$ & $\mathrm{C}$ & $\mathrm{A}$ \\
\hline & $=1500$ & B & C & B & C & B & B & B & $\mathrm{C}$ & B & B & B & A & B & B & B & A & B & A \\
\hline & $=1501$ & A & $A$ & A & $A$ & A & $A$ & A & $A$ & A & $A$ & A & $A$ & A & $A$ & A & $A$ & A & $A$ \\
\hline \multirow{3}{*}{$=1501$} & $=1499$ & B & $\mathrm{C}$ & $\mathrm{B}$ & $\mathrm{C}$ & $\mathrm{B}$ & $\bar{B}$ & $\mathrm{~B}$ & $\mathrm{C}$ & $\mathrm{B}$ & $\mathrm{B}$ & $\mathrm{B}$ & $\mathrm{A}$ & $\mathrm{B}$ & $\mathrm{B}$ & $\mathrm{B}$ & $\mathrm{A}$ & $\mathrm{B}$ & $\mathrm{A}$ \\
\hline & $=1500$ & A & $A$ & A & $A$ & A & $A$ & A & $A$ & $\mathrm{~A}$ & $A$ & A & $A$ & A & $A$ & A & $A$ & A & $A$ \\
\hline & $=1501$ & A & $A$ & A & $A$ & A & $A$ & A & $A$ & A & $A$ & A & $A$ & A & $A$ & A & $A$ & A & $A$ \\
\hline
\end{tabular}

Table 6: Price dynamics of $P 01$ and $P 12$ (details in Tables 7, 8 and 9). 


\subsection{Price Dynamics in the Two Markets with Many Agents}

Exploring the dynamics of $P 01$ and $P 12$ when there are several companies at both levels of the supply chain requires many simulations. We have not yet undertaken them because this would require automation of the recognition of Patterns A, B and C (and, perhaps, D, E, etc.). This is left for future work. However, initial results obtained in a few cases with sight recognition seem to show that applying Rule 1, then Rule 2 and finally Rule 3 allows determining the dynamics of $P 01$ and $P 12$.

\section{Conclusions}

In this paper we have presented a model of market-mediated supply chains. Our purpose is to study how conceptual tools designed to control a single market may be extended to the control of linked networks of markets. Specifically, our model is based on the single auction and the bidding strategy proposed by Steiglitz and his colleagues. We replace their agents by company-agents represented with the first level of Supply Chain Council's SCOR model. Finally, we implemented our model within JASA and ran simulations with one or with two markets in sequence.

The results obtained from these simulations can be summarised as follows. First, only three patterns of price dynamics are obtained. Next, setting the parameters of a market-mediated supply chain is more complicated than just balancing (i) consumption of products, transformation capacities and supply of products, and (ii) consumption and production of money. In fact, market dynamics also play a role. In our model, such dynamics are influenced by the difference between the initial and the target levels of the inventories used to trade in an auction. We have identified and explained the relations between these initial conditions of the inventories and the three observed price dynamics. These relations are summarized by two rules predicting price dynamics. Finally, we studied the impact of the price dynamics in one market on the price dynamics in the other market. Our insights are summarized in a third rule.

In this paper, all agents have the same inventory target. The first task in extending this work would be to continue the study of the regularities found between price dynamics and the initial conditions of the simulation in order allow for different inventory targets. Such an extension may introduce new patterns of price dynamics, because stock outs may occur for reasons not considered with the scenarios considered in this paper (i.e. stock outs only occur here when the price drops to zero, which makes manufacturers unable to receive money from one market in order to buy in the other market). Another interesting point here deals with the fact that inventory targets should be optimised so that the agents reduce their inventory holding costs. In fact, all the behaviours explored in this paper arise from an automatic procedure for placing shouts in auctions, but no more "intelligent" decisions than these are made. Finally, we plan to study different topologies of networks instead of the sequential (straightline) structure considered in this paper; that is, we have so far only considered auctions linked in sequence and would also like consider auctions linked otherwise, for instance, in parallel. We believe these non-sequential topologies will require companies to each have several "source" and "deliver" inventories, instead of only one of each; these different inventories would trade in different auctions. For example, a manufacturer could have one "deliver" inventory selling in the bolt market, and two "source" inventories, one buying in the screw market and the other one in the nut market. Such an architecture is under construction for future research and publication.

\section{Acknowledgments}

This research was undertaken as part of the EPSRC-funded project on Market-Based Control of Complex Computational Systems (GR/T10664/01), and we are grateful for this support. We also thank Omar Baqueiro Espinosa, Andrew Byde, Andrew Dowell, Enrico Gerding, Nick Jennings, Tomasz Michalak and Steve Phelps for their comments and suggestions. 


\section{References}

Anthes, G. (2003). Agents of change. Computer World. http://www . computerworld.com/ printthis/2003/0,4814,77855,00 .html (accessed 19 July 2006).

Barbuceanu, M. and Fox, M. S. (1996). Capturing and modeling coordination knowledge for multiagent systems. International Journal on Cooperative Information Systems, 5(2 \& 3), 275-314.

Clearwater, S. H., editor (1996). Market-Based Control: A Paradigm for Distributed Resource Allocation. World Scientific: Singapore.

Cloutier, L., Frayret, J.-M., D’Amours, S., Espinasse, B., and Montreuil, B. (2001). A commitmentoriented framework for networked manufacturing coordination. International Journal of Computer Integrated Manufacturing, 14(6), 522-534.

Dobb, M. (1981). Theories of Value and Distribution Since Adam Smith. Cambridge University Press, 5 th reprint of the $2 \mathrm{~d}$ edition edition.

Dodd, C. and Kumara, S. R. T. (2001). A distributed multi-agent model for value nets. In Proc. 14th Int. Conf. on Industrial and Engineering Applications of Artificial Intelligence and Expert Systems (IEA/AIE), volume 2070 of Lecture Notes in Artificial Intelligence, pages 718-727, Budapest (Hungary).

Forrester, J. W. (1958). Industrial dynamics - A major breakthrough for decision-makers. Harvard Business Review, 36(4), 37-66.

Fox, M. S., Chionglo, J. F., and Barbuceanu, M. (1993). The integrated supply chain management. Internal report of the Enterprise Integration Laboratory, Department of Industrial Engineering, University of Toronto, Ontario, Canada.

Fox, M. S., Barbuceanu, M., and Teigen, R. (2000). Agent-oriented supply-chain management. International Journal of Flexible Manufacturing Systems, 12(2/3), 165-188.

Geoffrion, A. M. and Krishnan, R. (2003). E-business and management science - Mutual impacts (part 2 of 2). Management Science, 49(11), 1445-1456.

Lee, H. L., Padmanabhan, V., and Whang, S. (1997a). The bullwhip effect in supply chain. Sloan Management Review, 38(3), 93-102.

Lee, H. L., Padmanabhan, V., and Whang, S. (1997b). Information distortion in a supply chain: The bullwhip effect. Management Science, 43(4), 546-558.

Mizuta, H., Steiglitz, K., and Lirov, E. (2003). Effects of price signal choices on market stability. Journal of Economic Behavior and Organization, 52, 235-251.

Moyaux, T. and McBurney, P. (2006a). Modelling a supply chain as a network of markets. In Proceedings of the IEEE International Conference on Service Systems and Service Managament, (ICSSSM 2006), Troyes, France.

Moyaux, T. and McBurney, P. (2006b). Reduction of the bullwhip effect in supply chains through speculation. In C. Bruun, editor, Proceedings of the Symposium on Artificial Economics 2006, Lecture Notes in Economics and Mathematical Systems 584 (Springer), pages 77-89, Aalborg, Denmark.

Phelps, S. (2007). Evolutionary Mechanism Design. Ph. D thesis, University of Liverpool (U.K.). Forthcoming. 
Simchi-Levi, D., Kaminsky, P., and Simchi-Levi, E. (2000). Designing and Managing the Supply Chain. McGraw-Hill Higher Education.

Steiglitz, K. and Shapiro, D. (1998). Simulating the madness of crowds: Price bubbles in an auctionmediated robot market. Computational Economics, 12, 35-59.

Steiglitz, K., Honig, M. L., and Cohen, L. M. (1996). A computational market model based on individual action. In S. H. Clearwater, editor, Market-Based Control: A Paradigm for Distributed Resource Allocation, pages 1-27. World Scientific: Singapore.

Sterman, J. D. (1989). Modeling managerial behavior: Misperceptions of feedback in a dynamic decision making experiment. Management Science, 35(3), 321-339.

\section{A Detail of the two Auctions with one Seller and Buyer per Auction}

This appendix details the results summarised in Table 6. That is, Figures 7, 8 and 9 present the dynamics of $P 01$ and $P 12$ depending on the initial conditions of each of the four inventories Source0, Deliver1, Source 1 and Deliver 2 . Table 6 only presented the type of price dynamics of $P 01$ and $P 12$, while Tables 7, 8 and 9 show what happens in detail. The upper graph in any entry in Tables 7, 8 and 9 represents $P 01$, while the graph at the bottom is shows Market 12 .

The first point to note is that the price in these three figures has the same Patterns A, B and C, as summarised in Table 6. Next, we observe a relationship between $P 01$ and $P 12$. For example, we never have smooth fluctuations of both $P 01$ and $P 12$ at the same time. That is, if $P 01$ and $P 12$ both have Pattern $\mathrm{B}$, then their fluctuations are never sine-like. To see that, consider the case in which all inventories start at their target levels (i.e. case Source0Ini $=$ Deliver1Ini $=$ Source1Ini $=$ Deliver2Ini $=1500$, which is in the center of Table 8). According to what we observed in Subsection 4.1, we should obtain a Pattern B in both markets. Indeed, this is what we obtain, except that the smooth fluctuations have lost their regularity. This can be informally interpreted in this way: (i) the smooth fluctuations are caused by a seller feeling richer when his buyer feels poorer, and the other way around (see explanations about Pattern B in Subsection 4.1), but (ii) Manufacturer1 is both a seller in Market01 and a buyer in Market12. In (Moyaux and McBurney, 2006b), we related such an impact of one market on another to a consequence of the "bullwhip effect" (Forrester, 1958; Lee et al., 1997a,b) on prices. 


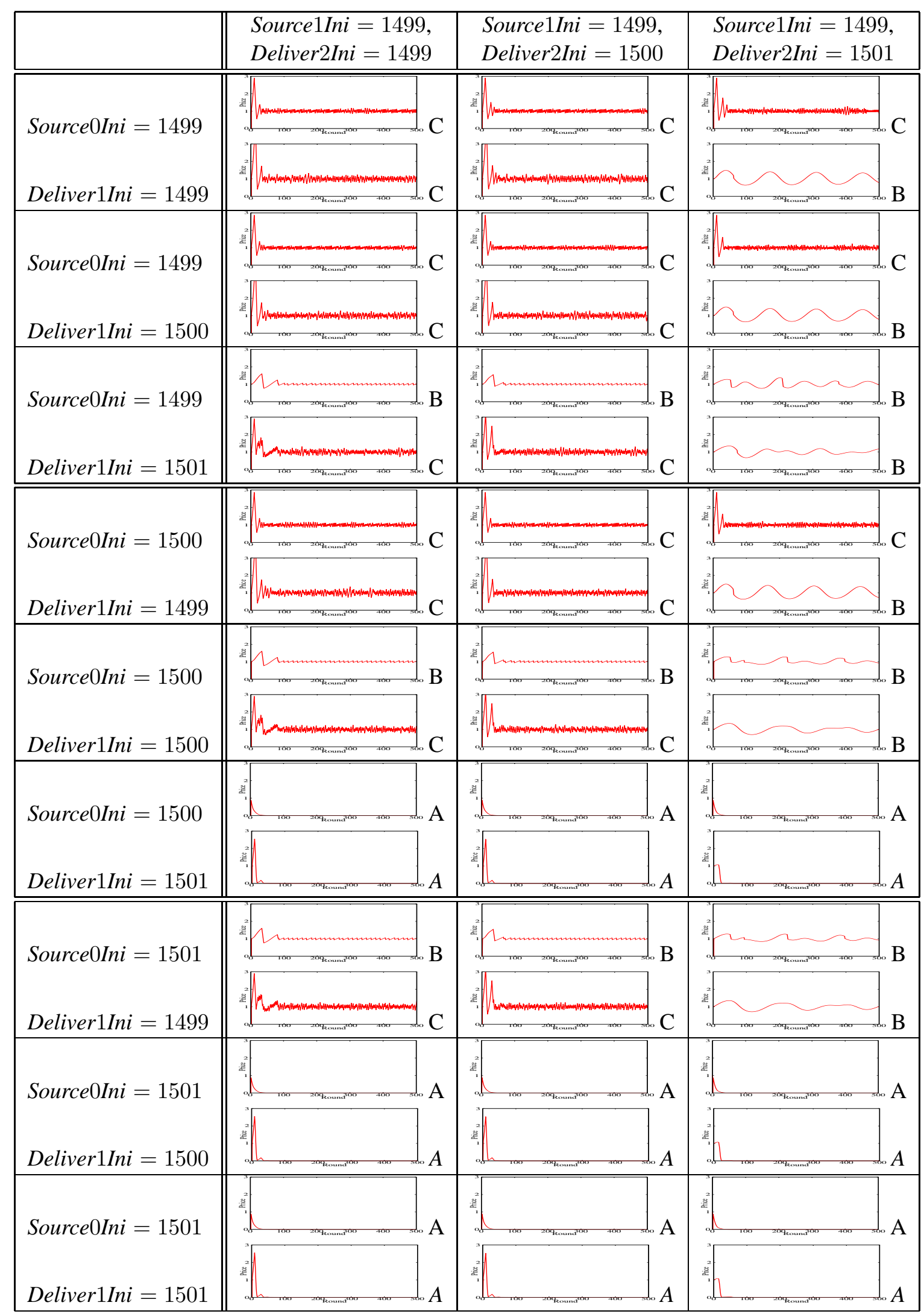

Table 7: Detail of Table 6 showing the price dynamics of $P 01$ on top and $P 12$ at bottom (1/3). 


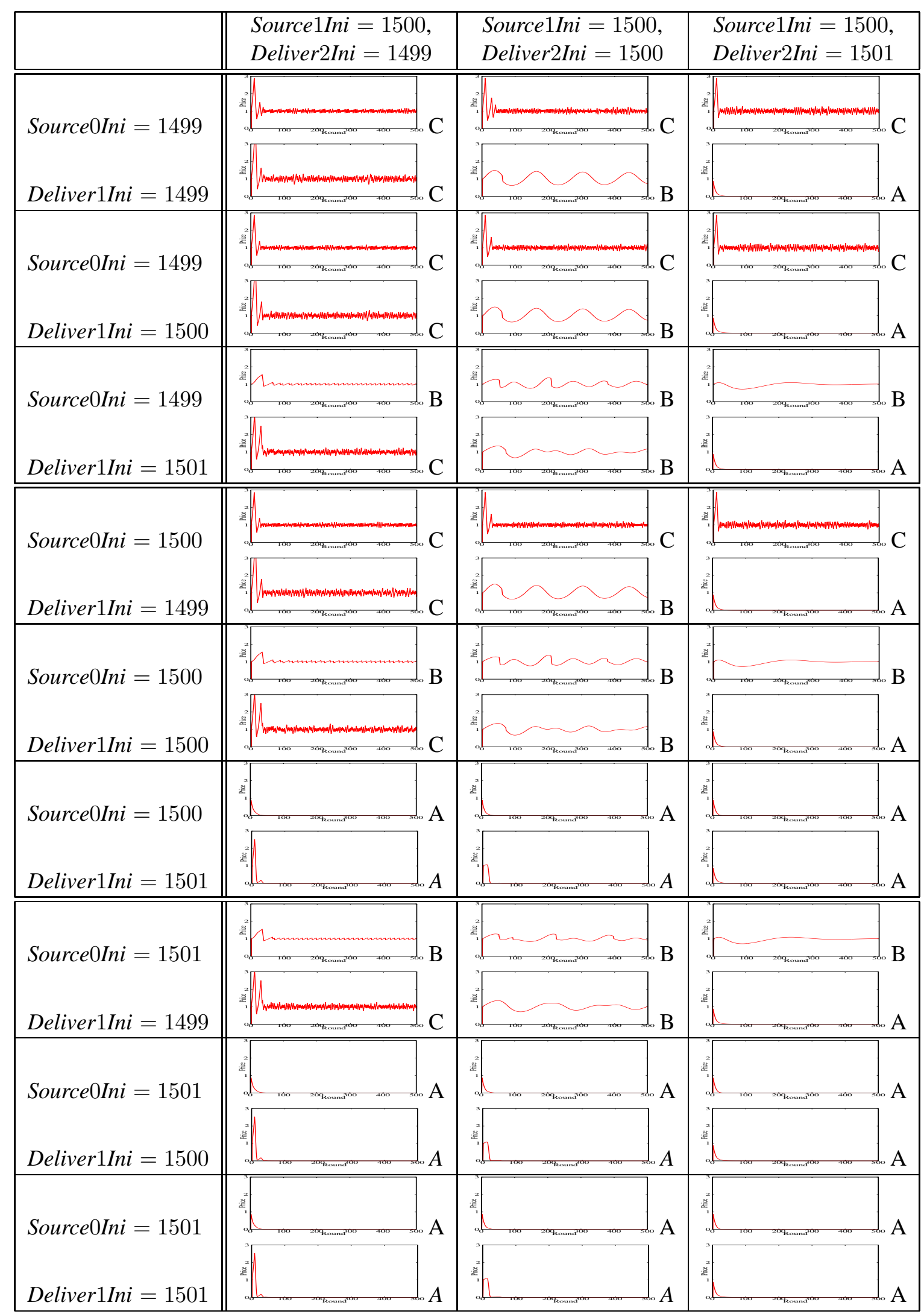

Table 8: Detail of Table 6 showing the price dynamics of $P 01$ on top and $P 12$ at bottom (2/3). 


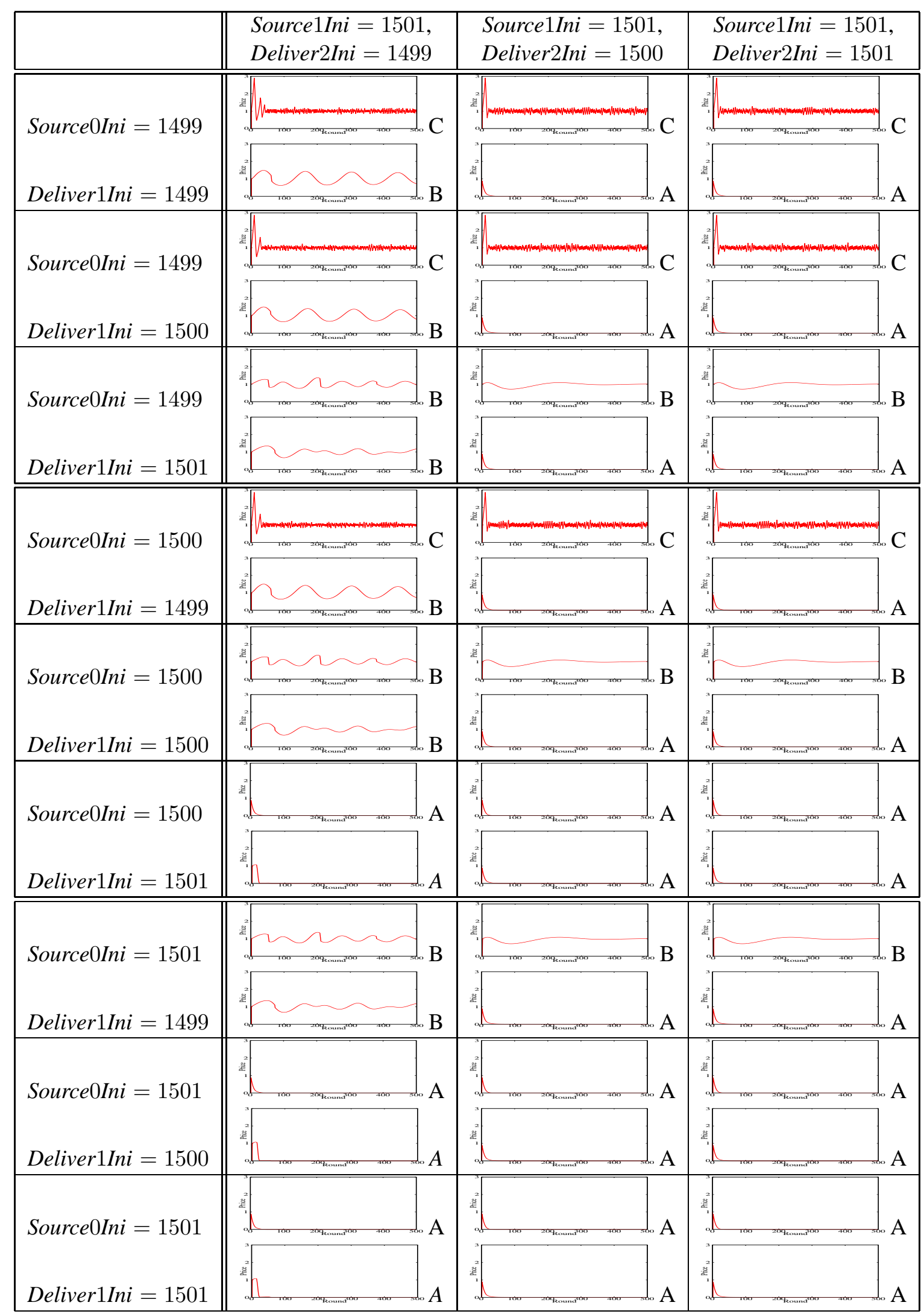

Table 9: Detail of Table 6 showing the price dynamics of $P 01$ on top and $P 12$ at bottom (3/3). 